\title{
A statistical look at plasmaspheric drainage plumes
}

\author{
Joseph E. Borovsky ${ }^{1}$ and Michael H. Denton ${ }^{2}$ \\ Received 18 December 2007; revised 6 March 2008; accepted 24 April 2008; published 16 September 2008.
}

[1] The properties of plasmaspheric drainage plumes are examined using cold-plasma measurements in geosynchronous orbit. During high-speed stream-driven storms, 210 plume crossings are collected and statistically analyzed. Plumes that persist for 4 days are common, which was the duration of our search. Plumes weaken with age, becoming narrower in local time with plasma that becomes less dense. Cold-plasma flow velocities are sunward in the plumes, with flow speeds decreasing as the storms progress. Plumes transfer typically $2 \times 10^{26}$ ions/sec (1.2 ton/hr of protons) when they are young, and the rate of transport decreases with plume age. A total of approximately $2 \times 10^{31}$ ions (34 tons of protons) are transported via plumes in the life of a storm. About half of the outer plasmasphere is drained in the first 20 hours of a storm. Large density fluctuations in the plumes indicate that the drainage plumes are lumpy, and large velocity fluctuations of the plasma flow indicate that the drainage plumes may be turbulent. Because of their persistence, drainage plumes are anticipated to be a regular feature of any ongoing geomagnetic storm.

Citation: Borovsky, J. E., and M. H. Denton (2008), A statistical look at plasmaspheric drainage plumes, J. Geophys. Res., 113, A09221, doi:10.1029/2007JA012994.

\section{Introduction}

[2] The plasmasphere is a cold $(\sim \mathrm{eV})$ dense plasma that resides in the dipolar portions of the Earth's magnetosphere [Lemaire and Gringauz, 1998]. The outer portions of the plasmasphere build up and drain away with geomagnetic-activity changes [e.g., Chappell et al., 1971; Carpenter et al., 1993; Elphic et al., 1997; Sandel and Denton, 2007]. During recurrent high-speed-stream-driven storms the outer plasmasphere goes through an episodic cycle of slowly building up in density and then rapidly draining (see Figure 1). The buildup of cold plasma to form the outer plasmasphere is caused by the diffusion of ionospheric plasma into magnetospheric flux tubes [e.g., Wilson et al., 1992; Bailey et al., 1997]. Building to a substantial density in the magnetosphere requires two or three days [Sojka and Wrenn, 1985; Lawrence et al., 1998; Su et al., 2001a], during which times the flux tubes must remain on closed drift orbits in the magnetosphere. Close to the Earth, the flux tubes of the magnetosphere corotate with the Earth's ionosphere; here the $\mathbf{E} \times \mathbf{B}$-drift paths of cold plasma remain within the magnetosphere making cyclic orbits around the Earth. Where the flux tubes remain in the magnetosphere for days or more, cold plasma builds up within them and they become plasmaspheric flux tubes. Further from the Earth the cold-plasma drift orbits are not

\footnotetext{
${ }^{1}$ Los Alamos National Laboratory, Los Alamos, New Mexico, USA.

${ }^{2}$ Department of Communication Systems, Lancaster University, Lancaster, UK.
}

Copyright 2008 by the American Geophysical Union. 0148-0227/08/2007JA012994\$09.00 confined within the magnetosphere and cold plasma does not build up to high densities since these flux tubes are short-lived. During geomagnetic quiet times the boundary between open and closed drift paths is farther from the Earth than it is during active times [e.g., Ejiri, 1978; Spiro et al., 1981]. Consequently, the quiet-time plasmasphere extends out to larger radii (higher L shells) than does the active-time plasmasphere [Carpenter and Park, 1973; Horwitz et al., 1990]. If geomagnetic activity is quiet for two or three days, the build up to high density will occur to radii beyond geosynchronous orbit and a robust outer plasmasphere will thus be formed (Figure 1b).

[3] When geomagnetic activity (i.e., magnetospheric convection) increases substantially, the outer plasmasphere will be "drained". A consistently occurring phenomenon during a drainage event is the plasmaspheric drainage plume, a swath of high-density (sometimes greater than $100 \mathrm{~cm}^{-3}$ ) cold plasma that flows from the inner magnetosphere to the dayside reconnection site (Figure 1c). Large drainage events occur when magnetospheric convection becomes strong after a long lull in geomagnetic activity. The best examples of this are in the early phases of geomagnetic storms that have been preceded by calm intervals [Borovsky and Steinberg, 2006; Denton and Borovsky, 2008]. About $66 \%$ of all high-speed-streamdriven (CIR-driven) storms and about $38 \%$ of all CMEdriven storms satisfy these conditions [Borovsky and Denton, 2006a]. These drainage plumes, intercepted by spacecraft at geosynchronous orbit $\left(6.6 R_{\mathrm{E}}\right)$, are the subject of this statistical study.

[4] Figure 2 contains two plots of the number density of cold plasmaspheric plasma as functions of the radial distance from the Earth in the equatorial plane from a model of 


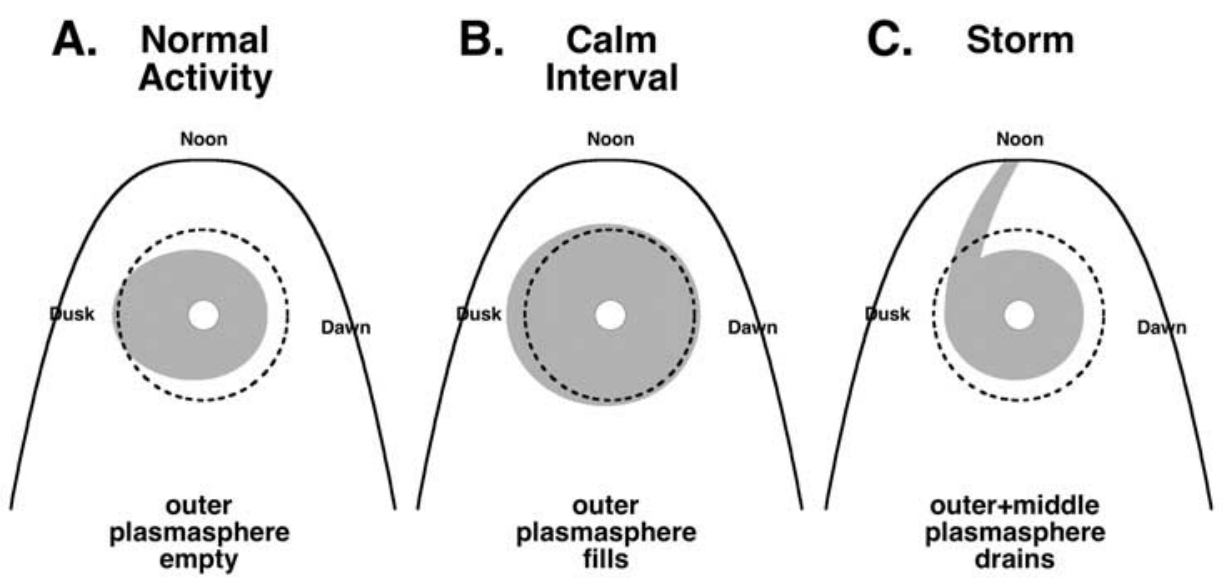

Figure 1. To demonstrate the gross behavior of plasmasphere as seen at geosynchronous orbit, the cut of the equatorial plane of the magnetosphere is sketched during three different times: (a) when geomagnetic activity is at normal levels, (b) when geomagnetic activity has been very low for a few days, and (c) well into a geomagnetic storm. In each, the outer black curve is the magnetopause, the inner solid circle is the Earth, and the larger dashed circle is geosynchronous orbit. The locations of the cool dense plasmaspheric plasma are shaded. Note in Figure 1c that a plasmaspheric drainage plume flows from the inner plasmasphere to the dayside reconnection site.

the plasmasphere by Gallagher et al. [1995]. The plot in the left panel is for prolonged weak geomagnetic activity and the plot in the right panel is for strong geomagnetic activity. By integrating these density values over the volumes of the dipolar flux tubes (assuming the plasmasphere fills the flux tubes with constant density to high latitudes), one finds that the hydrogen plasma of the "filled" plasmasphere during prolonged low activity has a mass of about $7 \times 10^{7} \mathrm{~g}$ (about 70 metric tons) and the hydrogen plasma of the "drained" plasmasphere during high activity has a mass of about $4 \times$ $10^{7} \mathrm{~g}$ (about 40 metric tons). Hence, when the outer plasmasphere drains, about 40 tons of protons are transported via the drainage plume. (Note that the drainage plume also conducts substantial amounts of $\mathrm{He}^{+}$and $\mathrm{O}^{+}$ to the dayside neutral line.) This 40 tons of protons dwarfs the mass of the hot plasmas of the magnetosphere, which are a few tons of protons.

[5] There are two important consequences to the fact that plasmaspheric plasma flows from the inner magnetosphere to the dayside reconnection site. Because it is cold plasma that moves only by $\mathbf{E} \times \mathbf{B}$ drift, the plasmaspheric plasma goes where the magnetic-field lines go, which is to the dayside reconnection site. Indeed, plasmaspheric-drainageplume plasma has been observed by spacecraft against the magnetopause [Elphic et al., 1996] and in the dayside reconnection site [Borovsky et al., 1997a; Su et al., 2000]. First, the fact that plumes cut across all $\mathrm{L}$ shells on the way to the reconnection site means that during geomagnetic storms there is some cold dense plasma on all $\mathrm{L}$ shells. Hence during storms plasma waves that favor dense cold
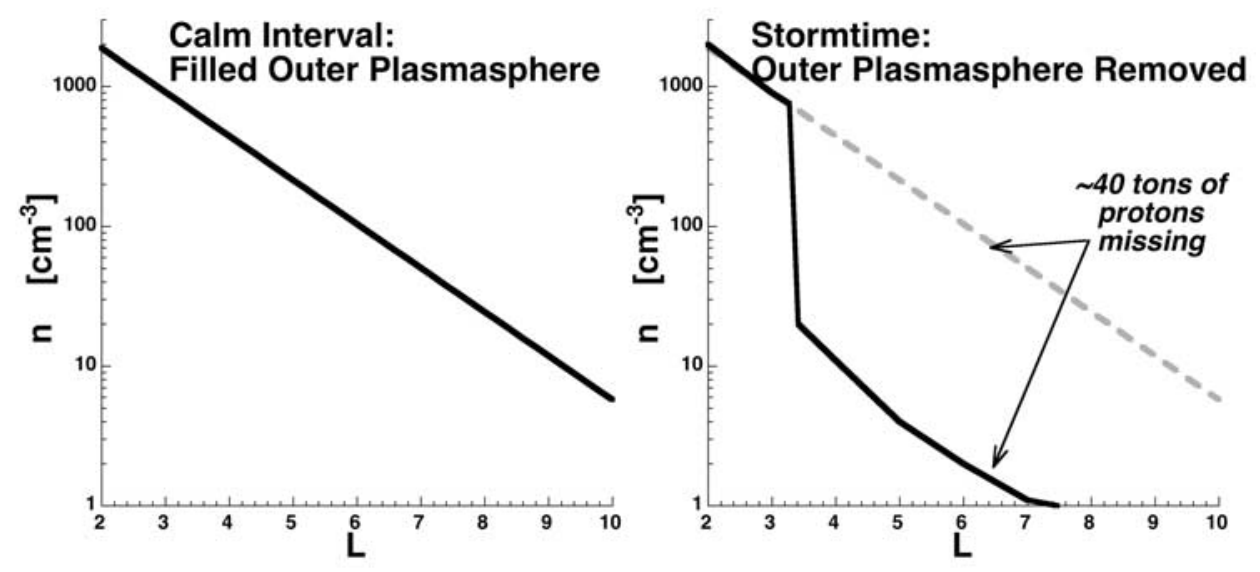

Figure 2. The cool-ion density of the plasmasphere is plotted as a function of L shell (after Gallagher et al. [1995] and see also Borovsky and Steinberg [2006]). The left is for a fully filled plasmasphere during an interval of weak geomagnetic activity; the right is for strong geomagnetic activity where the outer plasmasphere has been drained off. 
plasma can reside at all $\mathrm{L}$ shells. These plasma waves can impact the scattering and energization of radiation-belt particles. Three candidate plasmaspheric waves that can pitch-angle scatter relativistic electrons are plasmaspheric hiss [Horne et al., 2003; Meredith et al., 2004], whistlermode chorus [Tsurutani and Smith, 1974, 1977; Smith et al., 2004; Summers et al., 2004], and electromagnetic ioncyclotron (EMIC) waves [Summers and Thorne, 2003; Meredith et al., 2003]. Plasmaspheric hiss has been observed within plasmaspheric drainage plumes [Chan and Holzer, 1976; Hayakawa et al., 1986], whistler-mode chorus is theoretically expected to grow within plumes [Pasmanik et al., 1998], and EMIC waves are theoretically expected to grow within plumes [Kovalevskiy, 1980, 1981] and there is indirect evidence for them within plumes [Spasojevic et al., 2004]. Suspecting that plasma waves residing within the multitude of density gradients in clumpy drainage plumes will pitch-angle scatter relativistic electrons each time the electrons drift through the plume, Borovsky and Steinberg [2006] found that dropouts of the number density of relativistic electrons at geosynchronous orbit (with median durations of 11 hours) often coincided with confirmed spacecraft sightings of plasmaspheric drainage plumes.

[6] Second, the fact that the drainage plumes flow into the dayside reconnection site means that the dense plasmaspheric plasma can mass load dayside reconnection, reducing solar wind/magnetosphere coupling. This reduction of the coupling by drainage plumes was statistically observed in solar wind/magnetosphere data comparisons [Borovsky and Denton, 2006b] and was observed in 3D MHD simulations of the solar-wind-driven magnetosphere [Borovsky et al., 2008].

[7] A still outstanding question is where does the plasmaspheric-plume plasma go after the flux tubes are opened by dayside reconnection [Freeman et al., 1977; Elphic et al., 1997; Su et al., 2001b] and does this drained plasma impact the mechanics of the magnetosphere [Borovsky et al., 2008; Borovsky and Steinberg, 2006].

[8] Plasmaspheric drainage plumes are of interest for their roles in ring-current evolution [Thorne et al., 2006; Jordanova et al., 2007] and radiation-belt dynamics [Borovsky and Steinberg, 2006; Thorne et al., 2006; Borovsky and Denton, 2008, 2006b] and for their effect on solar wind/magnetosphere coupling [Borovsky and Denton, 2006b; Borovsky, 2008; Borovsky et al., 2008]. There is also substantial interest in the ionospheric signatures of drainage plumes [Su et al., 2001c; Foster et al., 2002, 2007; Spasojevic et al., 2004].

[9] Certainly, some things are known about plasmaspheric drainage plumes. They occur during elevated magnetospheric convection [Spiro et al., 1981], during both high-speed-stream-driven storms [Borovsky et al., 1998] and CME-driven storms [Thomsen et al., 1998], and their local-time positions can be predicted with simple magnetospheric-convection models [Weiss et al., 1997]. The cold plasma in the plumes flows sunward [Borovsky et al., 1998; Matsui et al., 1999; Goldstein et al., 2004; Denton and Borovsky, 2008], the plumes reach the dayside magnetopause [Elphic et al., 1996] and cold plasma flows into the magnetopause reconnection site [Borovsky et al., 1997a; Su et al., 2000]. Drainage plumes are wider and have higher plasma densities in storms with calms before the storms than they are in storms without prior calms [Denton and Borovsky, 2008]. The plasmas in plumes are strongly clumped [Spasojevic et al., 2003; Moldwin et al., 2004; Goldstein et al., 2004]. Plasmaspheric drainage plumes are spatially associated with plasma waves [Chan and Holzer, 1976; Hayakawa et al., 1986] and are temporally associated with radiation-belt dropouts [Borovsky and Steinberg, 2006]. Still, very little is known quantitatively about the properties of plasmaspheric drainage plumes.

[10] In this report plasmaspheric drainage plumes measured by the MPA plasma analyzers in geosynchronous orbit will be statistically analyzed to gain a baseline knowledge about the properties of the drainage plumes. Information about the densities, widths, plasma flow velocities, mass fluxes, and lumpiness of plumes will be obtained; measurements of the amount of plasma transport in the plumes will be made; and information about the temporal evolution and durations of the plumes will be obtained.

[11] This manuscript is organized as follows. In section 2 the plasma instrumentation used to measure drainage plumes and the selection of events is discussed. Section 3 contains the main findings of the statistical survey of 210 satellite crossings of plasmaspheric drainage plumes. Section 4 contains a discussion of turbulent flow in drainage plumes and contains suggestions for future research. The findings are summarized in section 4.

\section{Drainage Plumes as Observed at Geosynchronous Orbit}

[12] Plasmaspheric drainage plumes are analyzed using the multispacecraft MPA instruments [Bame et al., 1993] in circular geosynchronous orbits $\left(6.6 R_{\mathrm{E}}\right)$ at the geographic equator. The MPA instruments measure three-dimensional ion and electron distribution functions every 86 seconds over the energy range $1 \mathrm{eV}$ to $40 \mathrm{keV}$. Each distribution function is acquired in 10 seconds. The geosynchronous spacecraft charge negatively with respect to the ambient plasma enabling efficient analysis of the cool-ion populations of the magnetosphere. For a detailed analysis of this negative spacecraft charging, see Borovsky et al. [1998] and Thomsen et al. [1999]. In this study, moments of the distributions of plasmaspheric ions will be used, specifically the number density $n$, the east-west flow velocity $v_{\mathrm{ew}}$, and the radial flow velocity $v_{\mathrm{r}}$. The MPA instruments are energy analyzers and cannot discern the ionic composition of the plasmasphere, which varies with F10.7 and with the solar cycle [Brace et al., 1968; Newberry et al., 1989; Craven et al., 1997]; moments of the measured distributions are produced by assuming all ions collected are protons [Thomsen et al., 1999]. If the ionic composition of the plasmasphere is $70 \% \mathrm{H}^{+}, 20 \% \mathrm{He}^{+}$, and $10 \% \mathrm{O}^{+}$[e.g., Figure 4.8 of Lemaire and Gringauz, 1998], then the actual plasma number density is 1.21 times the value produced by MPA. Also, for the same ionic composition, the actual flow velocities would be 0.825 times the MPA-produced flow velocities.

[13] Decades of observations of the cold plasma at geosynchronous orbit have produced a systematic picture of the gross behavior of the plasmasphere as a function of geomagnetic activity, a picture that largely agrees with 

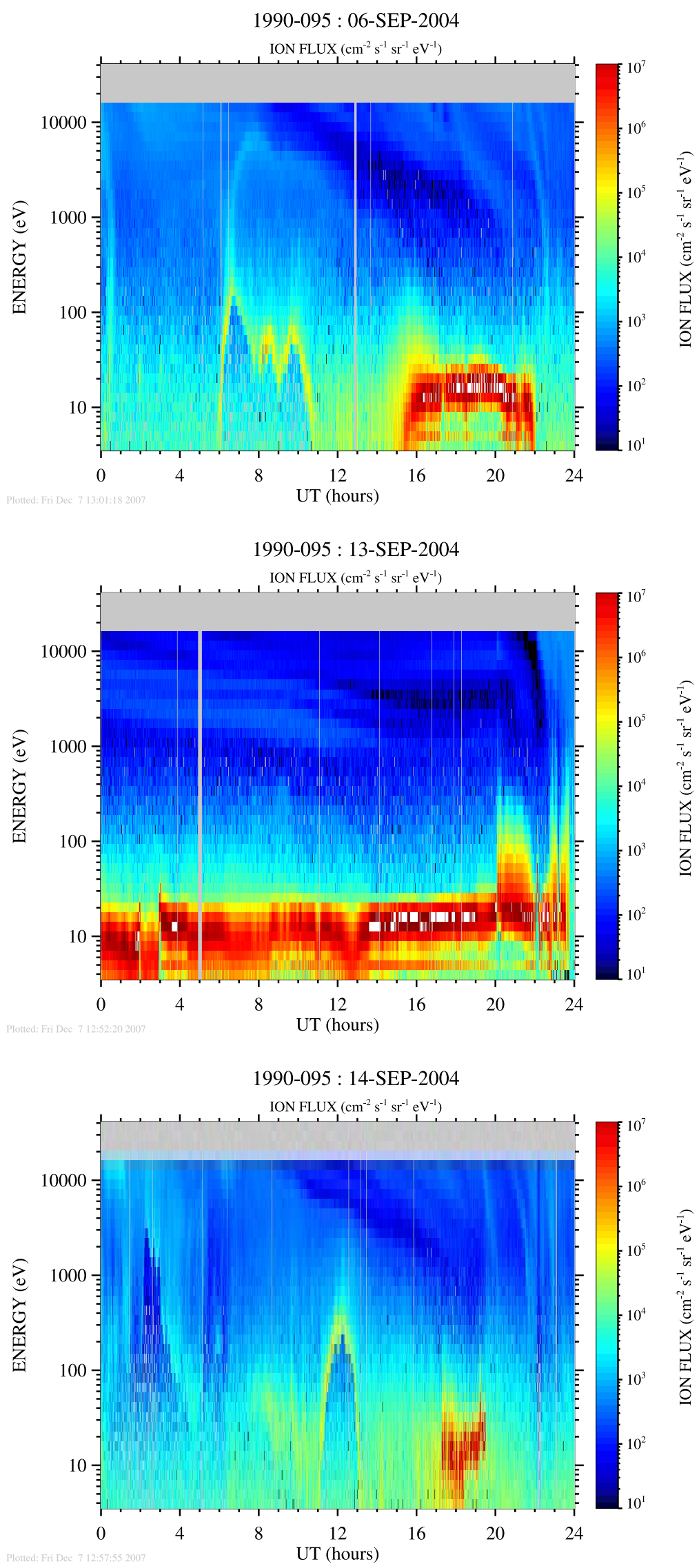

Figure 3 


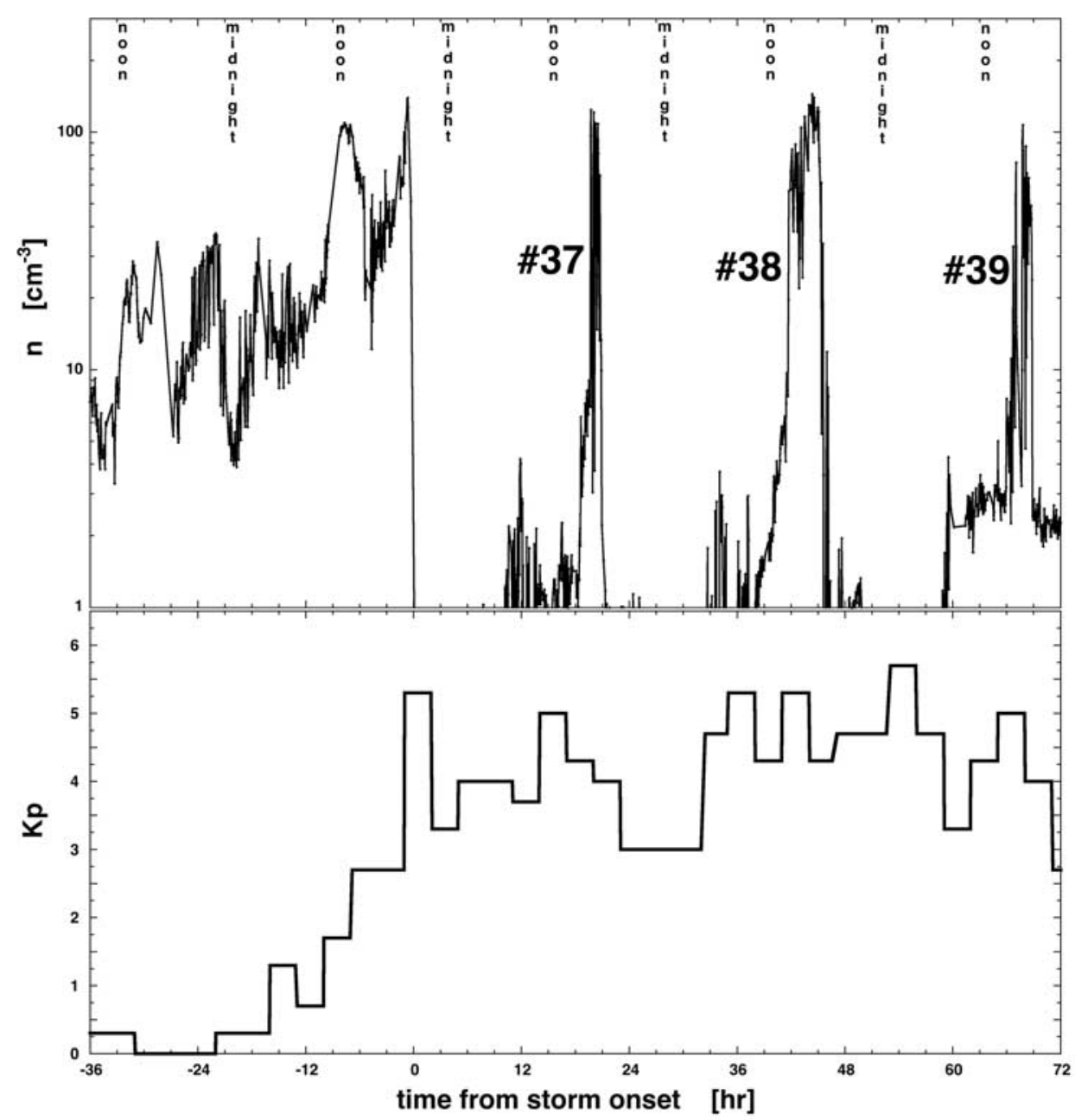

Figure 4. For 1.5 days prior to a storm onset and for 3 days afterward, the cold-plasma number density measured by one satellite in geosynchronous orbit is plotted as a (top) function of time, and the (bottom) $\mathrm{Kp}$ index is plotted. Drainage-plume crossings 37, 38, and 39 from the plume-crossing collection are seen in the top.

models and simulations [e.g., Lambour et al., 1997; Weiss et al., 1997; Liemohn et al., 2006; Jordanova, 2006]. That picture is described as follows, with a caution to the reader that details of the behavior are left out. (For examples of deviations from the gross behavior described below see Carpenter et al. [1993], Moldwin et al. [1994], Hoogeveen and Jacobson [1997], Dent et al. [2003], Goldstein et al. [2003], and Sandel and Denton [2007].) When geomagnetic activity is at normal levels, a satellite in geosynchronous orbit encounters the plasmasphere once per day for a few hours of local time near dusk [e.g., Chappell et al., 1970; Higel and Lei, 1984]. This is sketched in Figure 1a and is shown in the 24-hour (one-orbit) MPA energy spectrogram in the top panel of Figure 3. In the spectrogram, ion energy fluxes are plotted in color as function of the ion energy (vertical axis) and time (horizontal axis). The spacecraft is at local midnight at $2.7 \mathrm{hrs}$ UT and is at local noon at $14.7 \mathrm{hrs}$
UT. On this day, the Kp index varies from $2^{-}$to $4^{-}$. As can be seen in Figure 3, the cold ions of the plasmaspheric bulge are encountered from about $15.5-22$ UT (which is, about 13 - 19 LT). (Note in the spectrograms of Figure 1 that the negative spacecraft potential pulls the cold ions in to an energy $>10 \mathrm{eV}$.) In a previous study of the cold plasma detected by MPA during elevated convection intervals Denton et al. [2005] found that the local-time width of the bulge is a function of $\mathrm{Kp}$, decreasing as convection levels increased. When geomagnetic activity has been very low for a day or so, the outer plasmasphere builds up and a satellite at geosynchronous orbit spends most of the day within the plasmasphere [e.g., Sojka and Wrenn, 1985; Su et al., 2001a]. This is sketched in Figure 1b and is shown in the middle ion spectrogram of Figure 3. During storm times the outer plasmasphere is stripped away by convection and drains via a plume across the dayside magnetosphere, as

Figure 3. Ion energy spectrograms for the MPA instrument onboard the spacecraft 1990-095 are shown for 3 days: in the top for a day with an ordinary level of geomagnetic activity (bulge); in the middle, for a day with very low geomagnetic activity (filled outer plasmasphere); and in the bottom, for a day during a storm (drainage plume). 

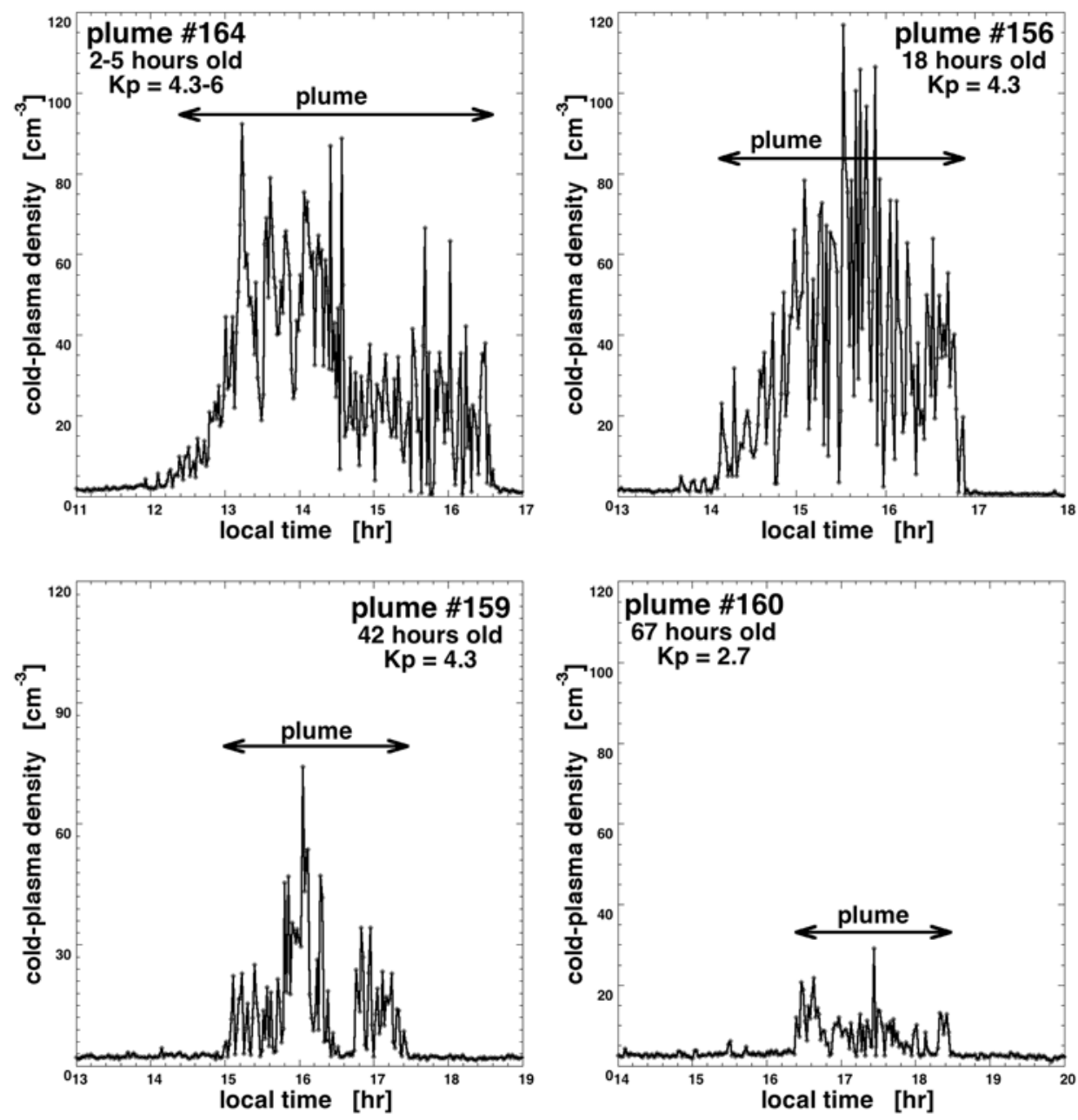

Figure 5. Four drainage plumes of various ages are shown.

sketched in Figure 1c. During these times a satellite in geosynchronous orbit crosses through the drainage plume once a day in the noon-to-dusk sector. This is shown in the bottom spectrogram of Figure 3. Note that drainage plumes (bottom spectrogram) are lumpier than bulge regions (top spectrograms), i.e., the density is very variable. The drainage plume plasma is also convecting sunward.

[14] In Figure 4 the number density of cold plasma as measured by MPA on one spacecraft in geosynchronous orbit is plotted for 4.5 days: 1.5 days prior to the onset of a high-speed-stream-driven storm and 3 days into the storm. The times at which the satellite is at local noon and local midnight are indicated at the top of the plot. In the bottom of Figure 4 the $\mathrm{Kp}$ index is plotted. As can be seen in the top panel, prior to the storm when $\mathrm{Kp}$ is very low (a "calm before the storm") the outer plasmasphere is seen at all local times. Afterward, during the storm the satellite crosses the drainage plume once per day, typically just after local noon.

Table 1. Properties of Plasmaspheric Drainage Plumes ${ }^{\mathrm{a}}$

\begin{tabular}{|c|c|c|c|c|}
\hline & Symbol & Young Plume & Change With Increasing Age & Fit Formula \\
\hline Local-time position & LT & $15 \mathrm{hr}$ & moves duskward & $15+0.019 t$ \\
\hline Width & $W$ & $4 \mathrm{hr}$ & narrows & $4.0-0.024 t$ \\
\hline Number density & $n$ & $33 \mathrm{~cm}^{-3}$ & less dense & $33 \mathrm{e}^{-t / 78 \mathrm{hr}}$ \\
\hline Corrected number density & $n^{*}$ & $40 \mathrm{~cm}^{-3}$ & less dense & $40 \mathrm{e}^{-t / 78 \mathrm{hr}}$ \\
\hline Lumpiness & $\delta n / n$ & 0.57 & no change & \\
\hline Radial flow velocity & $v_{\mathrm{r}}$ & outward $6 \mathrm{~km} / \mathrm{sec}$ & slower & $5.9-0.059 t$ \\
\hline East-West flow velocity & $v_{\text {ew }}$ & westward $10 \mathrm{~km} / \mathrm{sec}$ & slower & $-9.6+0.039 t$ \\
\hline Corrected radial flow velocity & $v_{\mathrm{r}}^{*}$ & outward $6 \mathrm{~km} / \mathrm{sec}$ & slower & $4.9-0.049 t$ \\
\hline Corrected east-west flow velocity & $v^{*}{ }_{\text {ew }}$ & westward $10 \mathrm{~km} / \mathrm{sec}$ & slower & $-7.9+0.032 t$ \\
\hline Ion flux & $\left\langle n v_{\mathrm{r}}\right\rangle$ & $2.3 \times 10^{5} \mathrm{~cm}^{-2} \mathrm{sec}^{-1}$ & lessens & $2.3 \times 10^{7}-2.6 \times 10^{5} t$ \\
\hline Total ion number flux & $\mathrm{d} N / \mathrm{d} t$ & $2.0 \times 10^{26} \mathrm{ions} / \mathrm{sec}$ & lessens & $2.0 \times 10^{26} \mathrm{e}^{-t / 29 \mathrm{hr}}$ \\
\hline Total ion mass flux & $\mathrm{d} M / \mathrm{d} t$ & 1.2 tons $/ \mathrm{hr}$ & lessens & $1.2 \mathrm{e}^{-t / 29 \mathrm{hr}}$ \\
\hline
\end{tabular}

${ }^{\mathrm{a}}$ In the fit formulas, the age of the plume $t$ is in hours. 


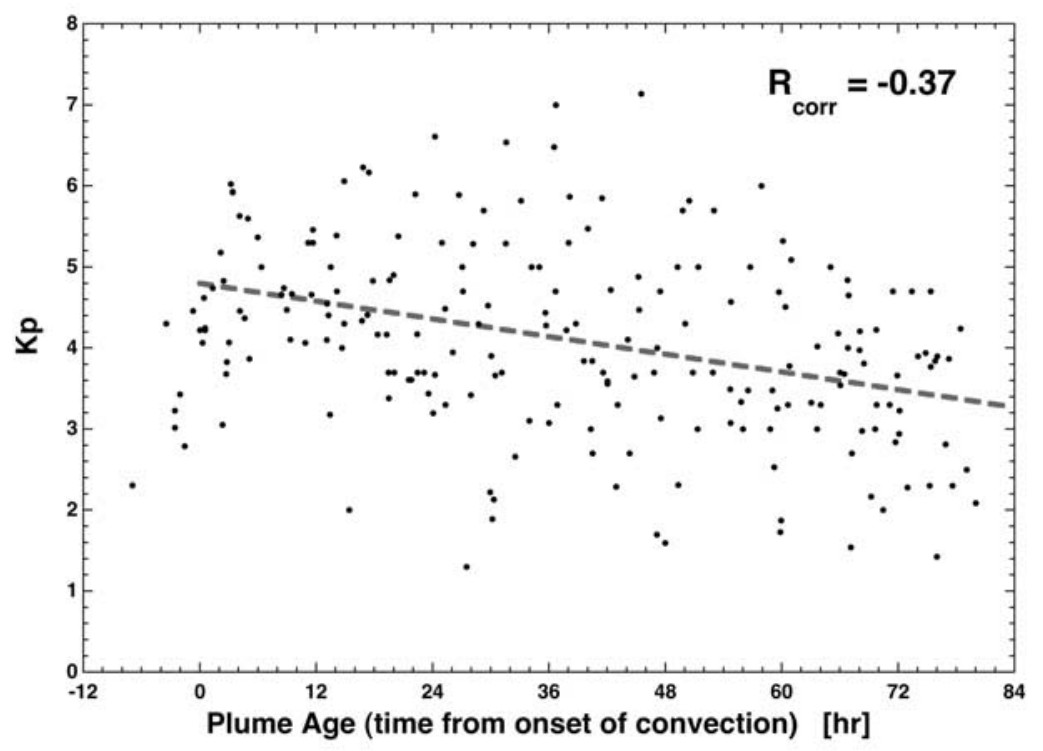

Figure 6. For 210 drainage-plume crossings, the mean value of $\mathrm{Kp}$ during each crossing is plotted as a function of the plume age $t$. The linear correlation coefficient is $R_{\text {corr }}=-0.32$. A linear regression fit to the $t>0$ data is shown as dashed curve.

The numbers on the top-panel plot indicate the number of the plume crossing in the catalog of crossings (see section 3.1). The drainage plumes are spotted by their high densities (tens of $\left.\mathrm{cm}^{-3}\right)$ and low temperatures $(\sim \mathrm{eV})$ with strong sunward flow. With higher resolution, four plumes of various ages are shown in the four plots of Figure 5: for easier comparison each plot has the same temporal extent (6 hours) and the same vertical scale. The drainage plumes are typically surrounded by broad regions of lower-density (typically $1-5 \mathrm{~cm}^{-3}$ ) warm (tens of $\mathrm{eV}$ ) plasma. Note in Figures 4 and 5 that the plumes are "lumpy".

\section{Statistics of Drainage Plumes}

[15] In this section 210 satellite crossings of plasmaspheric drainage plumes are used to statistically analyze the properties of drainage plumes at geosynchronous orbit. The results of the statistical analyses are collected into Table 1.

\subsection{Collection of Plume Crossings}

[16] Plasmaspheric drainage plumes during high-speedstream-driven storms are spotted using seven satellites carrying MPA plasma instruments. The plumes are easily discerned in the data set (see Figures 4 and 5): they are characterized by high-density flowing cold plasma. Typically the edges of a plume (entry and exit) are sharp. Drainage plumes are surrounded by lower-density warm (tens of eV) plasma. These "halo" regions can be seen in the logarithmic plot of density in Figure 4. The halo regions of warm plasma are not included as plumes. A brief discussion of the halo plasmas is deferred to section 4 .

[17] The data set examined to collect drainage plumes is the data set used for the superposed epoch study of highspeed-stream-driven storms of Denton and Borovsky [2008]. The storms were found by using the McPherron list of solar- wind stream interfaces [Robert McPherron, personal communication, 2007; McPherron and Weygand, 2006] and then examining temporal plots of the Kp index for storms following the stream interfaces. Then, for each storm in the collection, the onset time of convection (storm onset) is determined from a drop in MBI (midnight boundary index) [Gussenhoven and Madden, 1990]. MBI is an excellent indicator of magnetospheric convection, as is $\mathrm{Kp}$ [Thomsen, 2004], but MBI has higher time resolution than the 3-hour $\mathrm{Kp}$ index. The storm onset times were determined to about 30-minute accuracy. For every storm onset, 6 days of MPA data were extracted from the large MPA data set; the 6 days are extracted in a manner to guarantee that the data extends to at least 48 hours prior to the onset (a requirement for Denton and Borovsky [2008]) and at least 72 hours after the onset. Beyond 72 hours, a fraction of a day of data exists for each storm, with the size of that fraction depending on the UT of the convection onset. Hence the size of the data set (amount of coverage) is uniform for 2 days prior to the storm onsets and for 3 days after the onset. The size of the data set ramps down over the fourth day after onset.

[18] The search for plasmaspheric drainage plumes resulted in 210 plume crossings (one plume crossed by one satellite). The plumes are from the years 1993, 1994, 1995, 1996, 2003, and 2004.

[19] The properties of the plumes will be studied chiefly as functions of the age of the plumes (time since convection onset of the storm). Since the Kp index typically declines through the age of a storm, there is a $\mathrm{Kp}$ bias versus the age of the plume. This is noted in Figure 6, where the mean value of $\mathrm{Kp}$ during each plume crossing is plotted as a function of the mean value of the time since convection onset for each plume crossing. A linear fit to the data is shown as the dashed line. The linear correlation coefficient of the data is $R_{\text {corr }}=-0.37$, which is at the 2.8 -sigma level of correlation as compared with random, which is $2 / \mathrm{N}^{1 / 2}=$ 


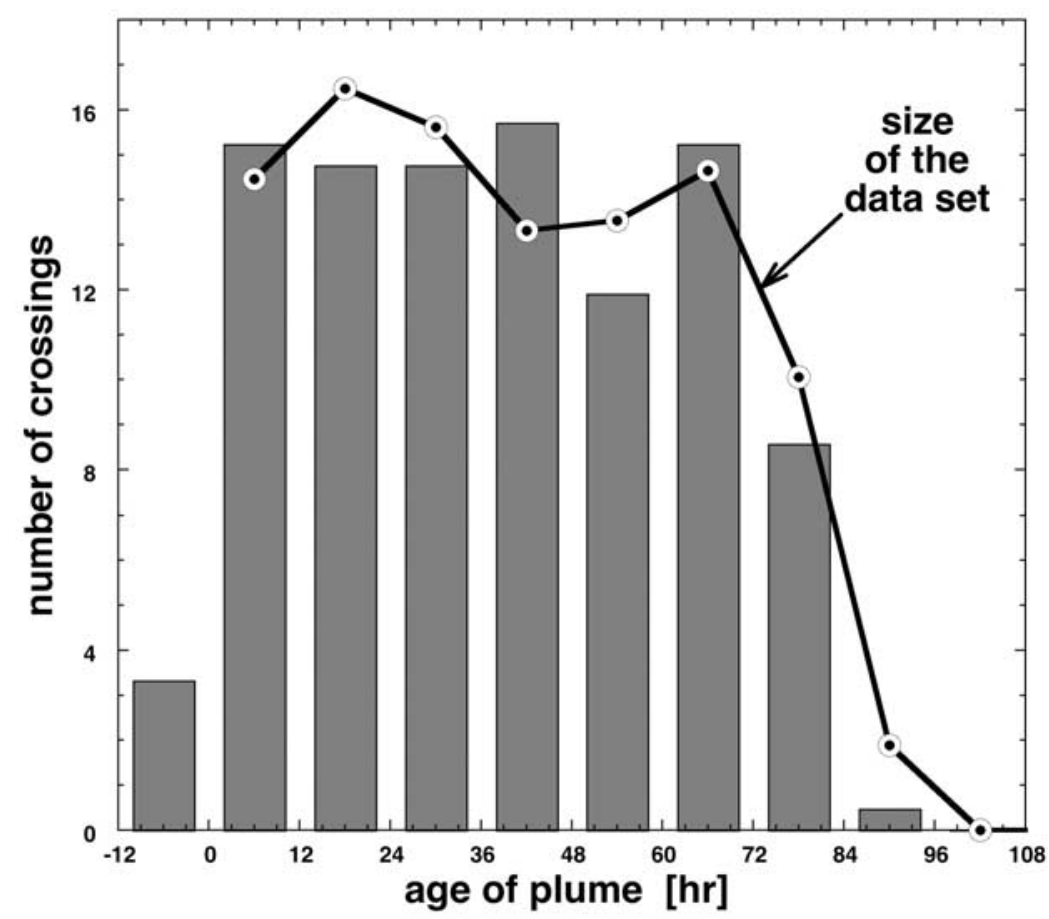

Figure 7. The number of drainage plumes found in the data set is binned as a function of the age of the plumes (bars). The size of the $t>0$ portion of the data set searched (in units of percent) is plotted as solid curve.

0.13 for $\mathrm{N}=210$ measurements [cf. Hald, 1952]. Figure 6 clearly shows the trend of lower Kp for the crossings of older plumes.

\subsection{Duration of Drainage Plumes}

[20] The duration (lifetimes) of the drainage plumes is examined by looking at the number of drainage plumes found as a function of the age of the plumes. In Figure 7

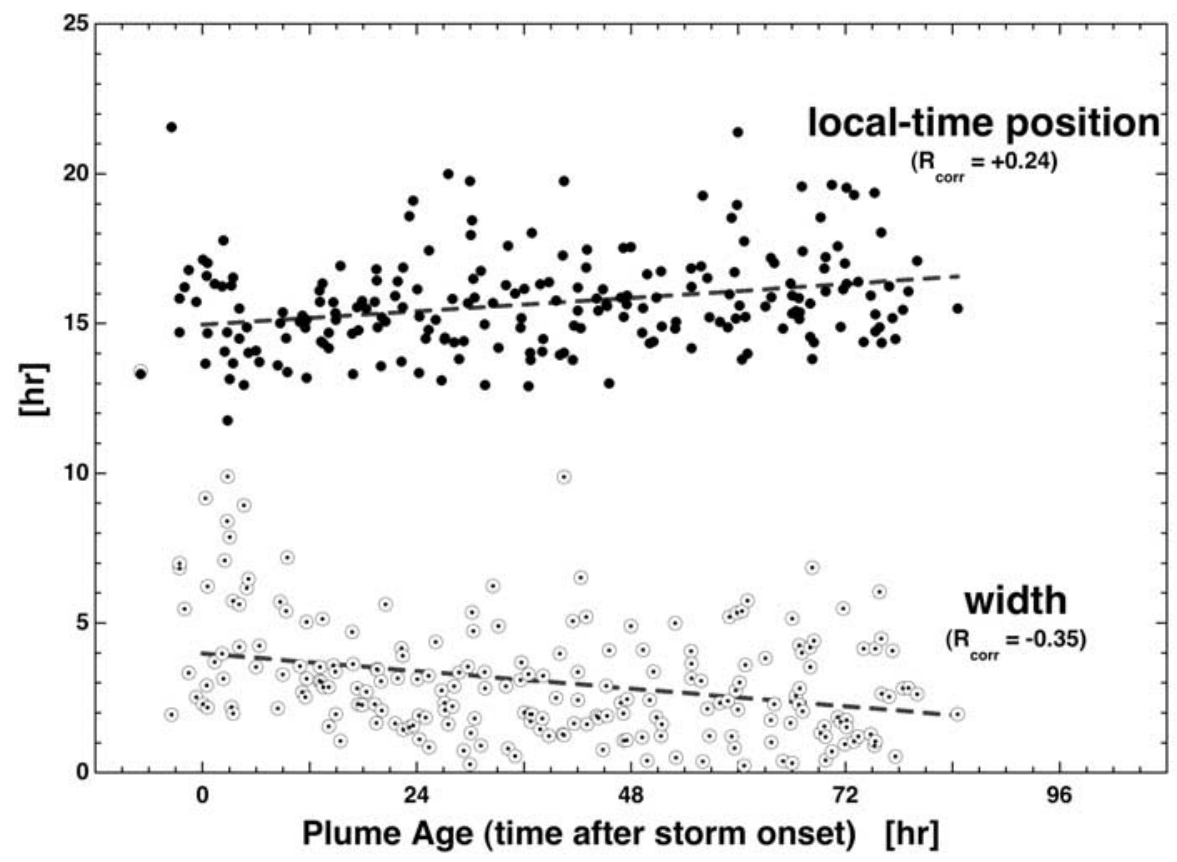

Figure 8. For 210 drainage-plume crossings, the mean local-time position of each plume (solid points) and the local-time width of each plume (hollow points) are plotted as functions of the plume age $t$. Linear regression fits to the $t>0$ data are shown as dashed curves. 


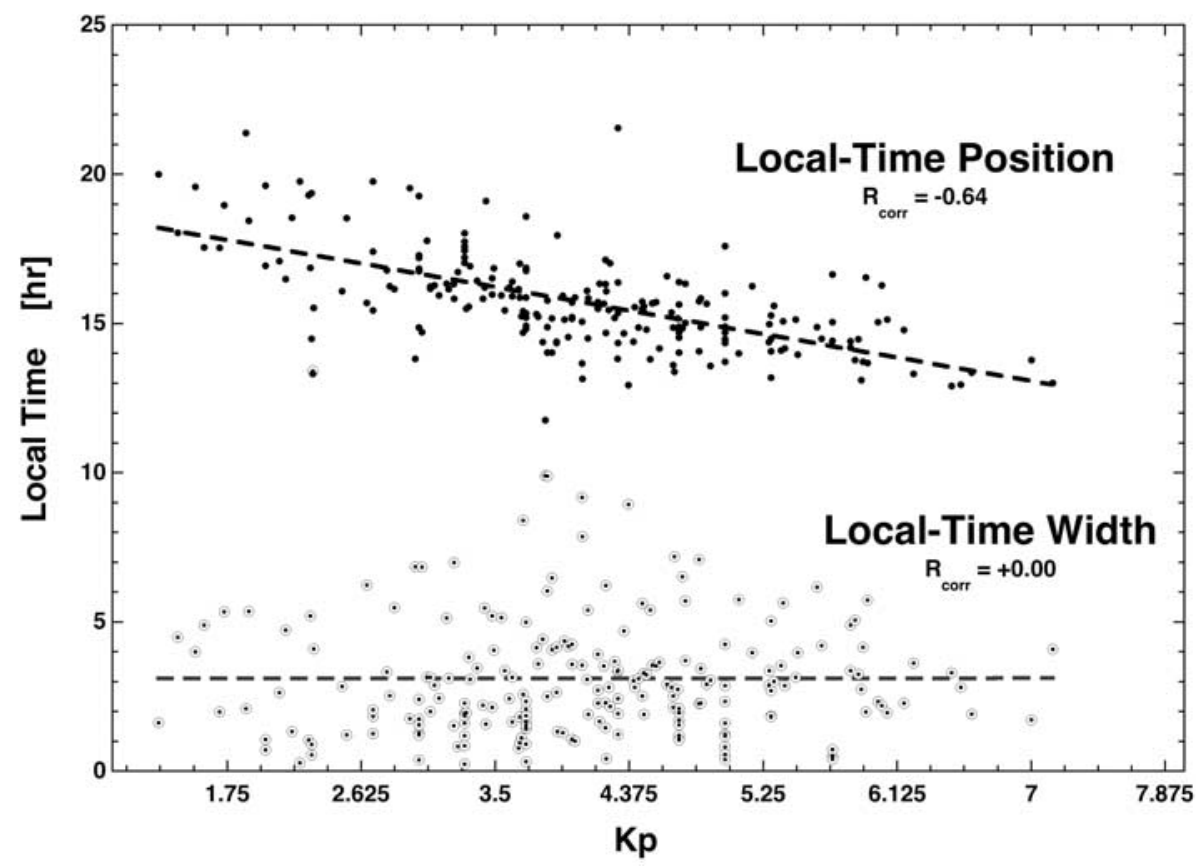

Figure 9. For 210 drainage-plume crossings, the mean local-time position of each plume (solid points) and the local-time width of each plume (hollow points) are plotted as functions of the mean value of Kp during each plume crossing. Linear regression fits to the $t>0$ data are shown as dashed curves.

the number of plume crossings in the data set is binned as a function of the age of the plumes (time since the onset of convection in the storms). As can be seen, for 72 hours after onset there is no noticeable falloff in the number of plumes found. The falloff in the number of plumes seen beyond 72 hours reflects a falloff in the size of the data set searched for plumes, as noted by the black curve.

[21] It is clear from Figure 7 that drainage plumes can last for several days if convection in the magnetosphere is sustained, as it is for high-speed-stream storms. We will find in later sections that the plumes become weaker (narrower and less dense) with age, but at the age of 84 hours they are not too weak to be found.

\subsection{Plume Local-Time Positions}

[22] In Figure 8 the mean local-time position (local-time location of the center of the plume) of the 210 plume crossings are plotted (solid points) as a function of the mean time after convection onset. As can be seen, the plumes cross geosynchronous orbit at $\sim 15$ LT when they are young, and move duskward as they age. A linear regression fit (shown as the dashed curve in Figure 8) for the age $>0$ plumes for the local-time position (in hr) versus age is

$$
\mathrm{LT}=15 \mathrm{hr}+\mathrm{t} / 53
$$

where $t$ is the plume age in hours. This expression is entered into Table 1.

[23] A Kp bias may explain the local-time trend duskward as the plumes age. In Figure 9 the local-time position of the 210 plumes is plotted (solid points) as a function of the mean value of $\mathrm{Kp}$ during each plume crossing. A linear regression fit to the data for the local-time position versus $\mathrm{Kp}$ is

$$
\mathrm{LT}=19 \mathrm{hr}+1.1 \mathrm{hr} \mathrm{Kp}
$$

As can be seen the plumes are closer to noon when $\mathrm{Kp}$ is high and closer to dusk when $\mathrm{Kp}$ is low. As demonstrated in Figure 6 , there is a trend of $\mathrm{Kp}$ being lower later in the storms when the plumes are older; hence the duskward shift with plume age may be caused by a lowering of $\mathrm{Kp}$.

\subsection{Plume Widths}

[24] The width is defined as the distance in local time between the entry into the plume and the exit from the plume. As will be discussed later, the plume plasma is lumpy and the plume flow appears to the turbulent. Hence the plume is probably billowy. When measuring the width as the point of first entry to the point of last exit, we are really measuring the width of an envelope that contains the plume material [cf. Corriveau and Baines, 1993; Anderson and Spall, 2001; Webster et al., 2003]. A complication to the measurement of plume widths is that magnetospheric convection may be episodic and plume plasma may, for instance, stop flowing and corotate while the spacecraft is crossing the plume, yielding an incorrect measurement of its width. This effect can lead to plume measurements that are either too wide or too narrow. In a statistical sense, since the entry edge of the plume has similar behavior to the exit edge of the plume, the average width of many plumes is fairly insensitive to such effects. However, the reader must be aware (1) that the widths measured here are the widths of the envelopes containing plume material and (2) that the individual plume-width measurements can be in error. 


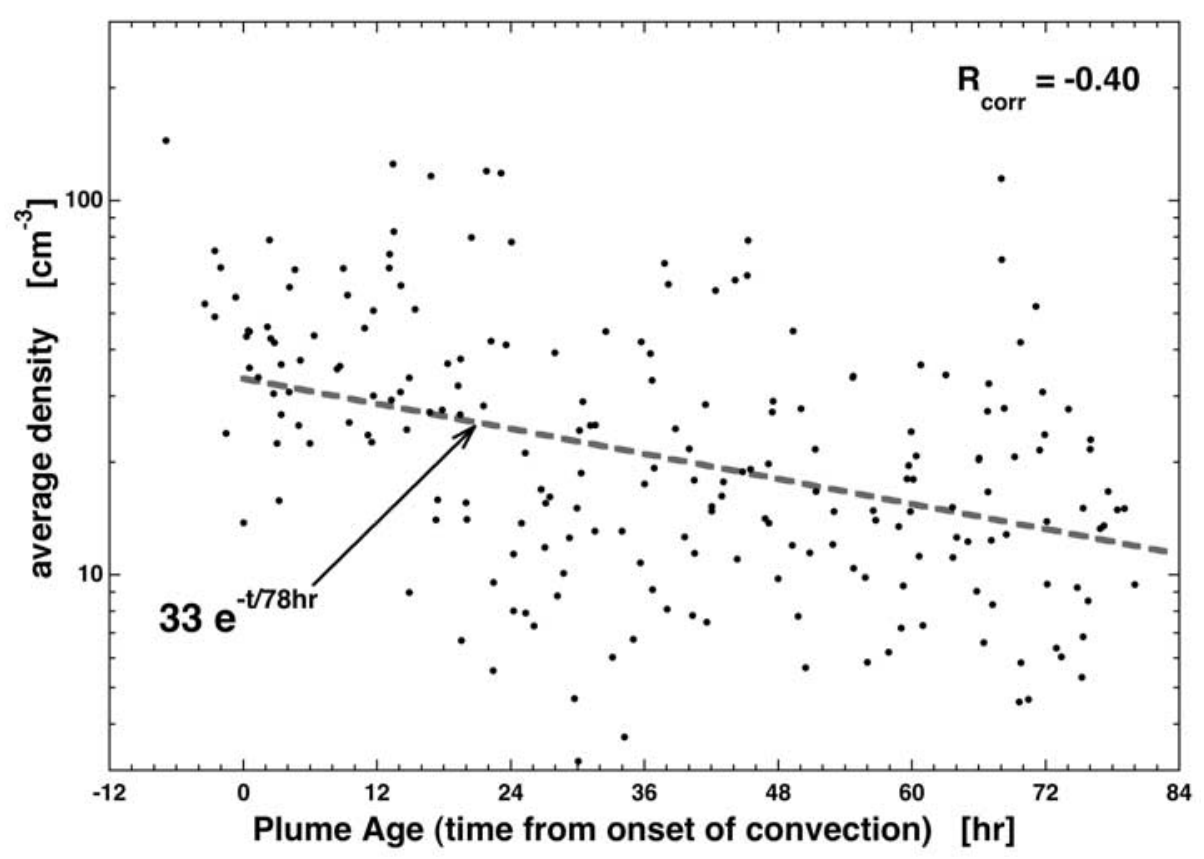

Figure 10. For 210 drainage-plume crossings, the mean value of the cold-plasma number density measured by MPA in each plume is plotted as a function of the plume age $t$. An exponential fit to the $t>0$ data is plotted as dashed curve.

[25] In Figure 8 the "widths" of the drainage plumes (in hours of local time) are plotted (hollow points) as a function of the age of the plume. As can be seen in Figure 8 there is a considerable spread to the widths. A linear regression fit to the age $>0$ data for the plume width (in hours) versus plume age yields

$$
\mathrm{W}=4.0 \mathrm{hr}-\mathrm{t} / 41,
$$

where $t$ is the plume age (in hours). At geosynchronous orbit, one hour of local time is equivalent to $10,950 \mathrm{~km}$ of travel along the orbit. Using this, expression (3) is rewritten for the width in $\mathrm{km}$ as

$$
\mathrm{W}=4.4 \times 10^{4} \mathrm{~km}-2.7 \times 10^{2} \mathrm{~km}(\mathrm{t} / 1 \mathrm{hr})
$$

(Note that expression (4) is not a straight-line distance, it is the distance along the arc of the circular orbit.) The values of the widths vary about a mean of about $4 \mathrm{hr}(44,000 \mathrm{~km})$ for young plumes, with the width decreasing with plume age.

[26] The decrease in the widths of plumes with plume age is probably not caused by the reduction of $\mathrm{Kp}$ with plume age. In Figure 9 the widths obtained in the 210 plume crossings are plotted as a function of the mean value of $\mathrm{Kp}$ in each crossing. As noted in the figure, the linear correlation coefficient between width and $\mathrm{Kp}$ is $\sim 0$.

\subsection{Plume Number Densities}

[27] As noted in section 2, the MPA instrument underestimates the density $n$ of plasma owing to the assumption that all ions collected are protons: for a $70 \% \mathrm{H}^{+}, 20 \% \mathrm{He}^{+}$, and $10 \% \mathrm{O}^{+}$plasma, a more-accurate value is obtained by multiplying by 1.21 . Whenever the MPA measured value of $n$ is "corrected" by multiplying by 1.21 , the corrected density will be denoted as $n^{*}$.
[28] In Figure 10 the average value of the measured coldplasma number density of each plume crossing is plotted (logarithmically) as a function of the age of the plume. This average density is calculated by summing all of the density measurements during one plume crossing and dividing the sum by the number of measurements in that crossing. The linear correlation coefficient between the plasma number density $n$ and the plume age is $R_{\text {corr }}=-0.40$. As can be seen in the plot, there is a large spread in the average of the plasma densities of the plumes and the plume plasma density tends to decrease with the age of the plume. An exponential fit to the age $>0$ data is

$$
\mathrm{n}=33 \mathrm{~cm}^{-3} \mathrm{e}^{-\mathrm{t} / 78 \mathrm{hr}},
$$

where $t$ is the age of the plume. Multiplying the measured density by 1.21 , the fit for the corrected density is

$$
\mathrm{n}^{*}=40 \mathrm{~cm}^{-3} \mathrm{e}^{-\mathrm{t} / 78 \mathrm{hr}}
$$

Younger plumes have measured average densities of $33 \mathrm{~cm}^{-3}$ $\left(n^{*}=40 \mathrm{~cm}^{-3}\right)$ and the average densities decrease with age. Note in Figure 8 that the plume widths also decrease with age.

[29] In Figure 10 the average of the plasma density varies from plume to plume. As can be seen in the plumes displayed in Figure 5, the plasma density within each single plume also varies considerably. These variations in the density within the plumes will be examined in section 3.8.

\subsection{Plume Plasma Flow Velocities}

[30] As noted in section 2, owing to the assumption made that all ions collected by the MPA detectors are protons, ion flow velocities are overestimated. For a $70 \% \mathrm{H}^{+}, 20 \% \mathrm{He}^{+}$, 

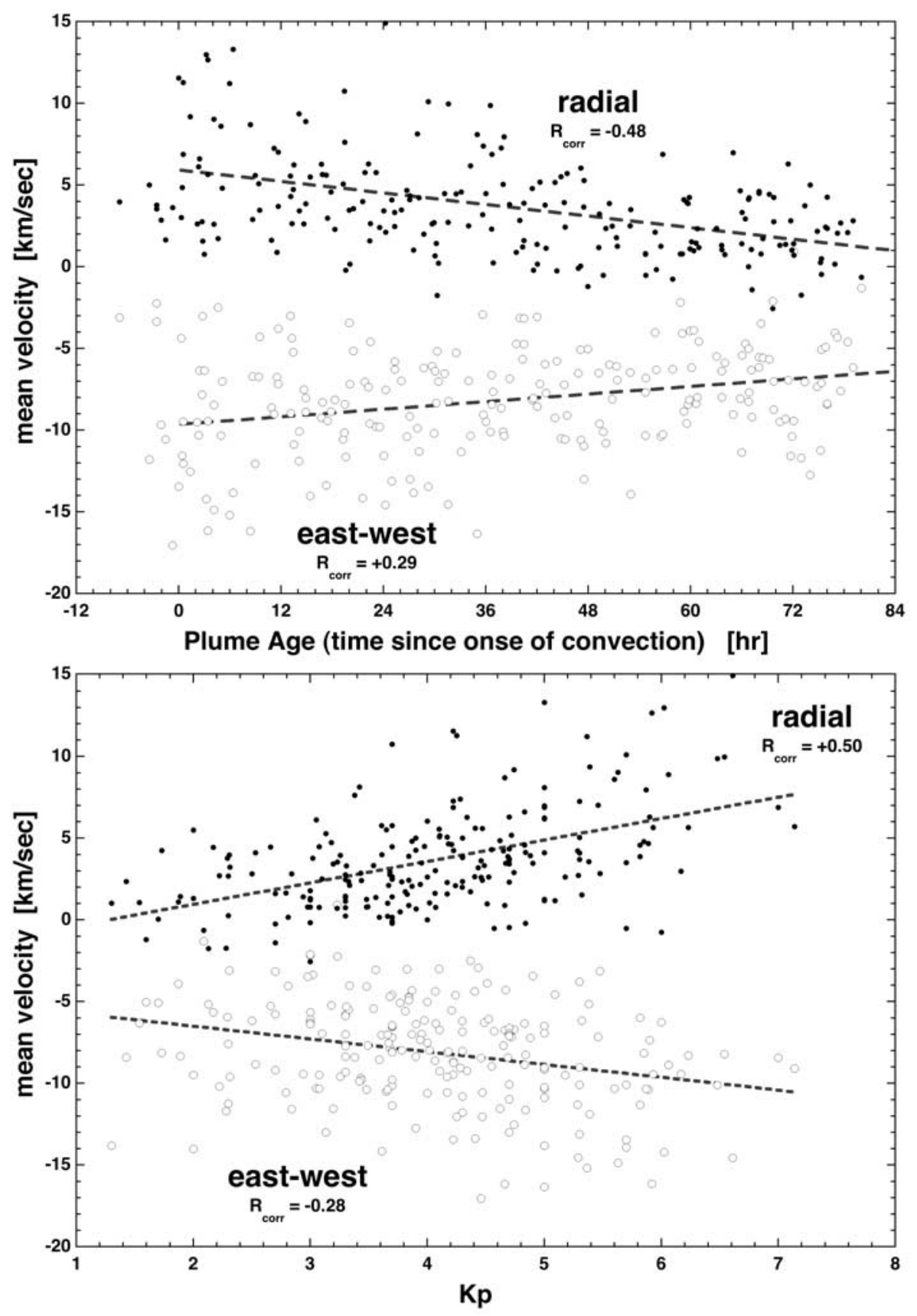

Figure 11. For 210 drainage-plume crossings, the mean value of the radial cold-plasma flow velocity $v_{\mathrm{r}}$ for each crossing (solid points) and the mean value of the east-west cold-plasma flow velocity $v_{\text {ew }}$ for each crossing (hollow points) are plotted as functions of the (top) plume age $t$ and the (bottom) mean value of $\mathrm{Kp}$ in each crossing. The eastward velocity of the spacecraft was removed. Linear regression fits to the $t>0$ data are shown as dashed curves.

and $10 \% \mathrm{O}^{+}$plasma, a more-accurate flow velocity is obtained by multiplying the measured flow velocities by 0.825 . Whenever the measured flow velocity $\mathrm{v}$ is "corrected" by multiplying by 0.825 , the corrected velocity will be denoted as $v^{*}$.

[31] In Figure 11 the average cold-plasma flow velocity of each plume crossing is plotted as a function of the age of the plume (top panel) and as a function of the average value of $\mathrm{Kp}$ for each plume crossing (bottom panel). The radial component of the flow velocity is $v_{\mathrm{r}}$ is plotted as the solid points and the east-west azimuthal component of the flow velocity $v_{\text {ew }}$ is plotted as the hollow points. Positive $v_{\mathrm{r}}$ is a flow that is radially outward and positive $v_{\mathrm{ew}}$ is a flow that is eastward along the direction of the spacecraft orbit. To change from the spacecraft measurement frame to the Earth's reference frame, the spacecraft's orbital velocity of $3 \mathrm{~km} / \mathrm{sec}$ is subtracted from the $v_{\text {ew }}$ measurements. Linear regression fits for $v_{\mathrm{r}}$ and $v_{\mathrm{ew}}$ are shown as the dashed lines 


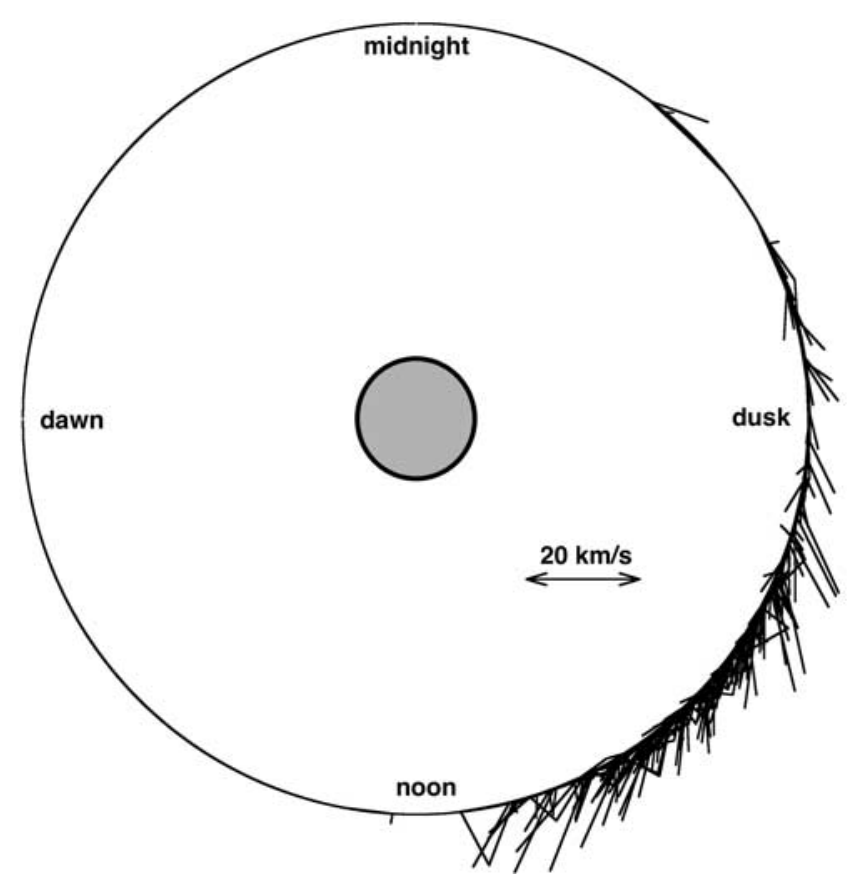

Figure 12. For the 210 plume crossings, the mean coldplasma flow velocities are depicted on the geosynchronous orbit where the plumes were measured.

in Figure 11. The linear regression fits for $v_{\mathrm{r}}, v_{\mathrm{ew}}, v_{\mathrm{r}}^{*}$, and $v_{\mathrm{ew}}^{*}$ versus plume age are collected into Table 1.

[32] As can be seen in the top of Figure 11, the mean flows are radially outward $\left(\mathrm{v}_{\mathrm{er}}>0\right)$ and westward $\left(v_{\mathrm{ew}}<0\right)$. The flow speeds are larger when the plume is young (early in the storm) and the flow speeds tend to decrease with plume age. In the bottom of Figure 11 it can be seen that the plume flow velocities tend to decrease with decreasing Kp, so the decrease in the plume plasma flow speed with age could be owed to the decreasing of $\mathrm{Kp}$ as the storm progresses.

[33] In Figure 12 the average-flow-velocity vectors for the 210 plume crossings are displayed along geosynchronous orbit. Each vector in the figure represents the mean flow vector for one plume crossing by one spacecraft. The base of each vector is located on the spacecraft orbit where the mean local-time position of the plume was, the length of the vector is proportional to the measured mean flow speed $\left(\mathrm{v}_{\mathrm{r}}^{2}+\mathrm{v}_{\mathrm{ew}}^{2}\right)^{1 / 2}$, and the direction of the vector is in the direction of the measured mean flow speed, where the length and direction are constructed from the mean value $v_{\mathrm{r}}$ and the mean value $v_{\mathrm{ew}}$. As can be seen, the plasma flows in the plumes are chiefly sunward. The flow pattern of the 210 plumes shown in Figure 12 is consistent with the measured flows within individual plumes in the literature [cf. Figure 3 of Borovsky et al., 1998 and Figures 2 and 5 of Matsui et al., 1999].

[34] More information about the plasma flow velocities in plumes will be found in sections 3.8 and 4.1.

\subsection{Mass Transport in Drainage Plumes}

[35] In "correcting" the number density $n$ and flow velocity $\mathrm{v}$ for the protons-only assumption made in the MPA data analysis, the two correction factors cancel so that the corrected number flux $n^{*} v^{*}$ is equal to the measured number flux $n v$. Hence no corrections of ion fluxes need be made.

[36] In Figure 13 the average value $\left\langle n v_{\mathrm{r}}\right\rangle$ of the radial ion flux $n v_{\mathrm{r}}$ for each plume crossing is plotted as a function of the age of the plume. The average $\left\langle n v_{\mathrm{r}}\right\rangle$ for a plume crossing is obtained by summing the individual $n v_{\mathrm{r}}$ measurements in the plume crossing and dividing by the number

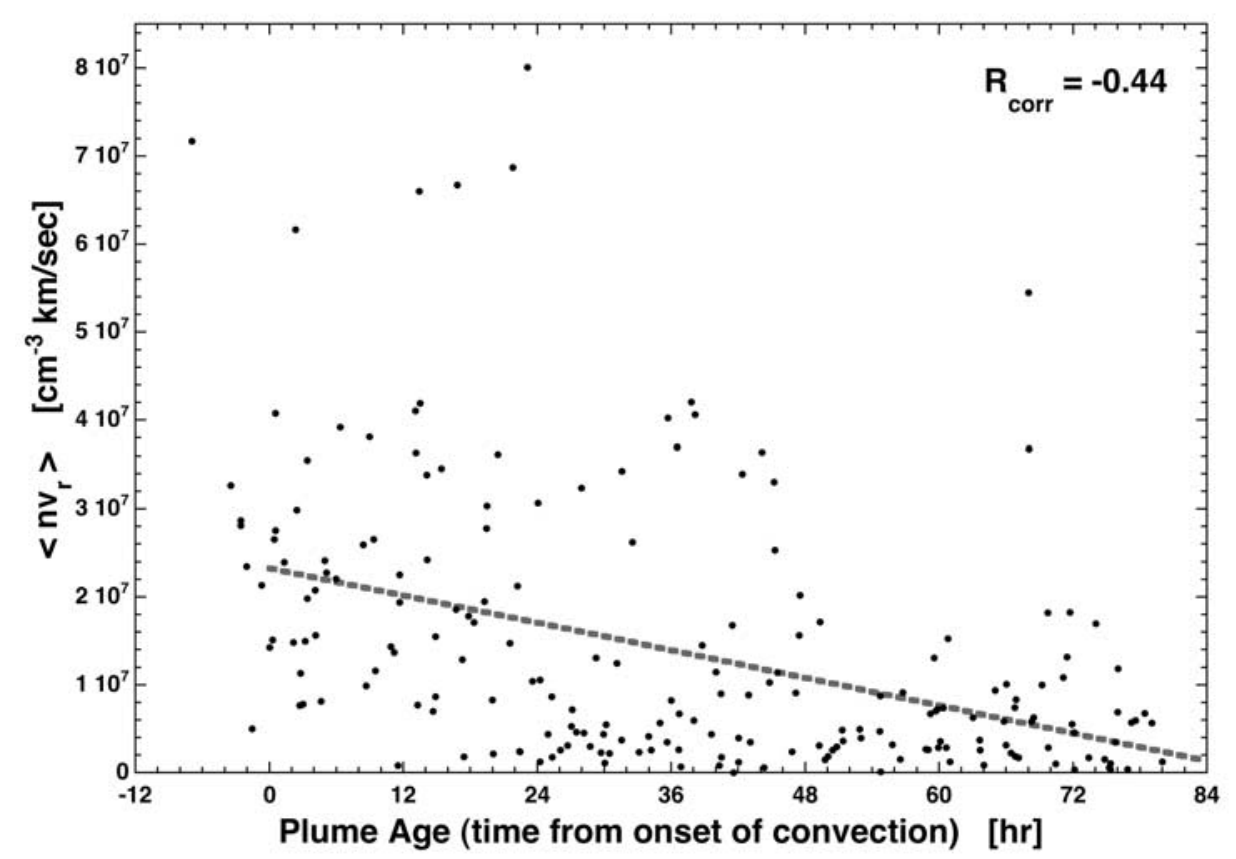

Figure 13. For 210 drainage-plume crossings, the mean radial ion flux for each crossing is plotted as a function of the plume age $t$. A linear regression fit to the $t>0$ data is shown as dashed curve. 

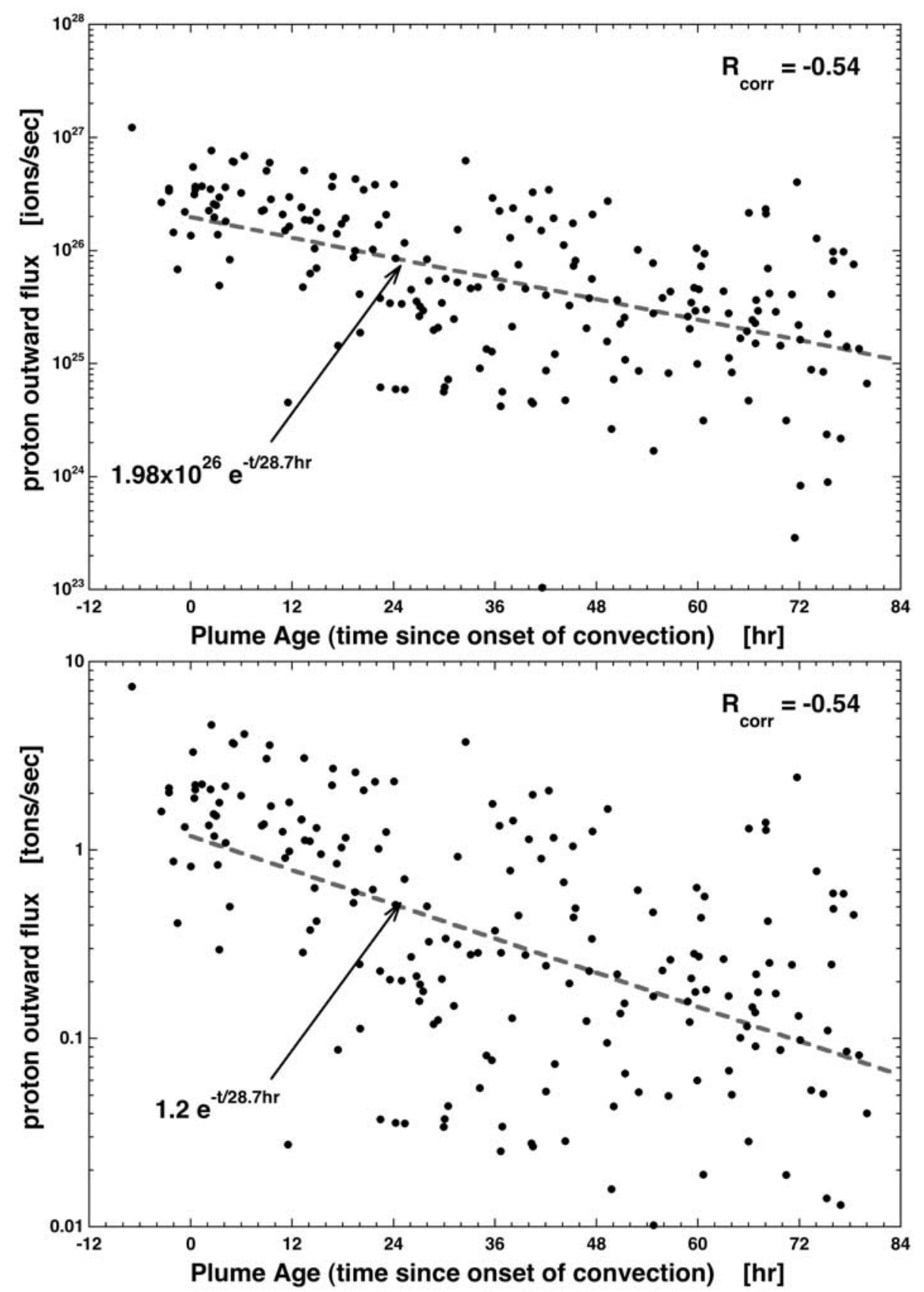

Figure 14. For 210 drainage-plume crossings, the total ion flux in the plume is plotted as a function of the plume age $t$. In the top, the units of the total ion flux are ions per second, and in the bottom, the units are tons of protons per hour. The linear correlation coefficient of the data is $R_{\mathrm{corr}}=-0.54$. Exponential fits to the $t>0$ data are shown as dashed curves.

of measurements in the crossing. The linear correlation coefficient between $\left\langle n v_{\mathrm{r}}\right\rangle$ and the plume age is $R_{\text {corr }}=$ -0.40 . A linear regression fit to the age $>0$ data is plotted as the dashed curve: that fit is

$$
\left\langle\mathrm{nv}_{\mathrm{r}}\right\rangle=2.3 \times 10^{7} \mathrm{~cm}^{-1} \mathrm{sec}^{-1}-2.6 \times 10^{5} \mathrm{~cm}^{-2} \mathrm{sec}^{-1} \mathrm{hr}^{-1} \mathrm{t},
$$

where $t$ is the age of the plume (in hours). As can be seen, the ion radial flux in the plumes is typically outward (positive) and the ion flux in the plumes decreases as the plumes age.

[37] From the measured radial ion fluxes in the plume crossing, estimates of the total transport of ions in the plumes can be made as follows. The radial ion flux $n v_{\mathrm{r}}$ measured every 86 seconds by MPA is integrated across the plume by summing the individual values of $n v_{\mathrm{r}}$ and multiplying by $2.62 \times 10^{7} \mathrm{~cm}$, which is the distance traveled by a geosynchronous satellite along its orbit 

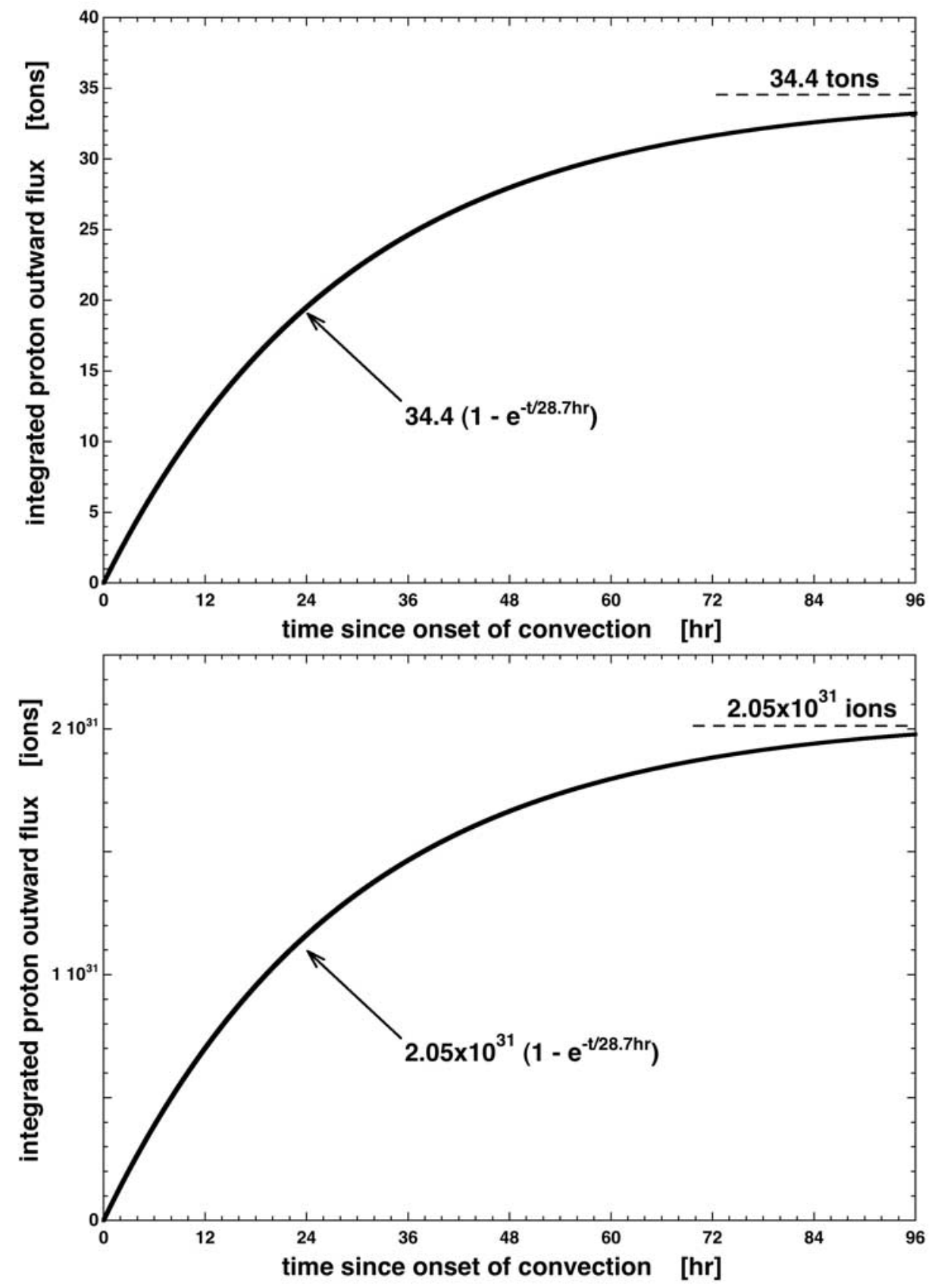

Figure 15. Time integrals of the exponential fits to the measured total ion fluxes are plotted as functions of time. In the top, the units are ions, and in the bottom, the units are tons of protons.

every 86 seconds. Multiplying the resulting number by the effective north-south height of the plume will yield a total ion flux in the plume. The effective height is obtained by integrating the volume of a $\mathrm{L}=6.6$ dipole flux tube from one ionosphere to the other, which yields $3.80 \times 10^{9} \mathrm{~cm}^{3}$ per unit area of the flux tube at the equator. This yields an effective height of $3.80 \times 10^{9} \mathrm{~cm}$, which is about $6 R_{\mathrm{E}}$. (Note that the ionosphere-to-ionosphere length of a field line in that flux tube is $16.2 R_{\mathrm{E}}$, which is much larger than the effective height; the effective height accounts for the convergence of the flux tube in calculating the flux-tube volume.) Assuming that the plume plasma has a uniform number density in the north-south direction [cf. Garcia et al., 2003], this is the effective height of the column of radially outward moving plume material. (Note that assuming the plasma density is uniform with height from the equator in a flux tube will suffice for making estimates, but may not be valid for detailed calculations.) Multiplying the summed $n v_{\mathrm{r}}$ values by $9.96 \times 10^{16} \mathrm{~cm}^{2}$ yields the total ion transport of the plume crossed. The total ion transport-rate values $\mathrm{d} N / \mathrm{d} t$ are plotted in the top of Figure 14 as a function of the plume age. The linear correlation coefficient between the 


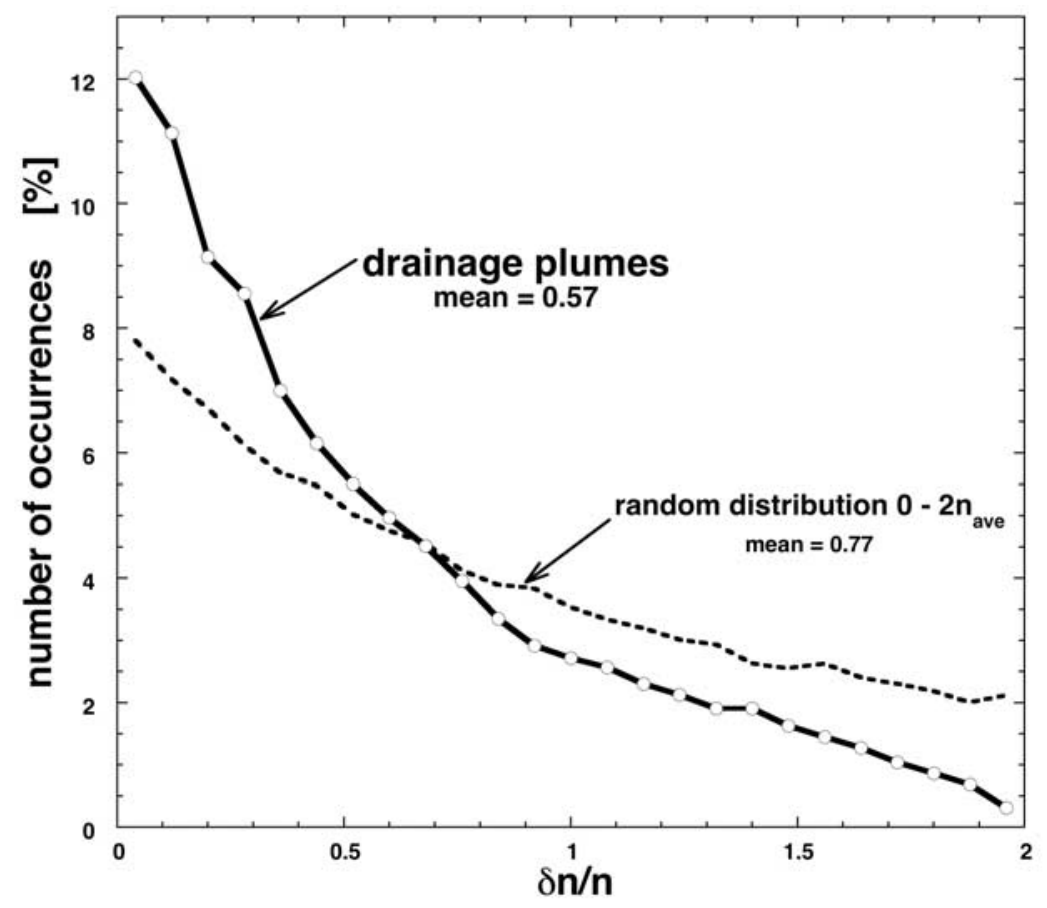

Figure 16. The fractional change in the measured cold-plasma number density over 86 seconds is binned to produce the occurrence distribution plotted as solid curve with hollow points. For comparison, the fractional change of a sequence of random numbers is binned as dashed curve.

transport-rate values $\mathrm{d} N / \mathrm{d} t$ and the plume age is $R_{\text {corr }}=$ -0.54 . An exponential fit to the $t>0$ data is

$$
\mathrm{dN} / \mathrm{dt}=1.98 \times 10^{26} \text { ions } / \mathrm{sec}^{-\mathrm{t} / 28.7 \mathrm{hr}}
$$

Converting these ion-transport-rate values from ions/sec to tons $/ \mathrm{hr}$ of protons (where 1 ton $=10^{3} \mathrm{~kg}$ ), the data is replotted in the bottom of Figure 14. An exponential fit to the data yields

$$
\mathrm{dM} / \mathrm{dt}=1.2 \operatorname{ton} / \mathrm{hr} \mathrm{e}^{-\mathrm{t} / 28.7 \mathrm{hr}} .
$$

for the proton transport rate. At early times the plumes transport 1.2 tons $/ \mathrm{hr}$ (or $1.98 \times 10^{26}$ ions $/ \mathrm{sec}$ ) radially outward past geosynchronous orbit. As can be seen in Figure 14, the transport rate of plasmaspheric plasma decreases with time as the storms progress.

[38] Earlier estimates of plume flow were consistent with the range of values seen in Figure 14: Elphic et al. [1997] estimated $3.7 \times 10^{26}$ ions $/ \mathrm{sec}$ for typical drainage plumes and Foster et al. [2004] estimated $1.5 \times 10^{27} \mathrm{ions} / \mathrm{sec}$ for an extremely large geomagnetic storm.

[39] To obtain an estimate of the total amount of plasma transported by a plume during a storm, expressions (38) and (39) can be integrated over time to yield the integrated transport as a function of plume age (time after onset of storm)

$$
\begin{gathered}
\mathrm{N}(\mathrm{t})=2.05 \times 10^{31} \operatorname{ions}\left(1-e^{-\mathrm{t} / 28.7 \mathrm{hr}}\right) \\
\mathrm{M}(\mathrm{t})=34.4 \operatorname{tons}\left(1-e^{-\mathrm{t} / 28.7 \mathrm{hr}}\right) .
\end{gathered}
$$

These integrals appear in Figure 15. As can be seen the total amount of plasma transported increases steadily early in a storm and then asymptotes to a final value. According to expressions (10), about half of the outer plasmasphere is drained in the first 20 hours of a storms. For the fit to the measurements of the drainage-plume crossings, the asymptotic value for the total amount of drainage in a long storms is $2.0 \times 10^{31}$ ions or 34.4 tons of protons. This value agrees with the $\sim 40$ ton mass of the missing outer plasmasphere obtained in section 1 with the use of the Gallagher model. Borovsky and Steinberg [2006] had a similar estimate and Borovsky et al. [1997a] estimated $1 \times 10^{31}$ ions are drained.

\subsection{Lumpiness of Drainage Plumes}

[40] As can be seen by examining the plumes at 86second-time resolution in Figures 4 and 5, the plasma density varies considerably in 86 seconds of motion. The spacecraft velocity of $3 \mathrm{~km} / \mathrm{sec}$ across the plume is dwarfed by the plasma flow velocity which is $\sim 15 \mathrm{~km} / \mathrm{sec}$. It is likely that the temporal variations of the density seen are lumps swept past the spacecraft in the plume flow. In that case the 86 -sec cadence corresponds to $\sim 1300-\mathrm{km}$ spatial sampling of the plume plasma. (Also, the 10-second snapshot time to make a distribution function corresponds to $150 \mathrm{~km}$ of flow of the plasma past the spacecraft.)

[41] Using the MPA measurements of cold-plasma density, which are 10-second snapshots of the plasma made every 86 seconds, the fractional variance $\delta n / n$ is calculated and analyzed. Here, $\delta n / n=2\left(\mathrm{n}_{2}-\mathrm{n}_{1}\right) /\left(\mathrm{n}_{1}+\mathrm{n}_{2}\right)$, where $\mathrm{n}_{1}$ and $\mathrm{n}_{2}$ are two sequential measurements of the density separated by 86 seconds. In Figure 16 the occurrence distribution of $\delta n / n$ for 19,655 measurements of plume density is binned 


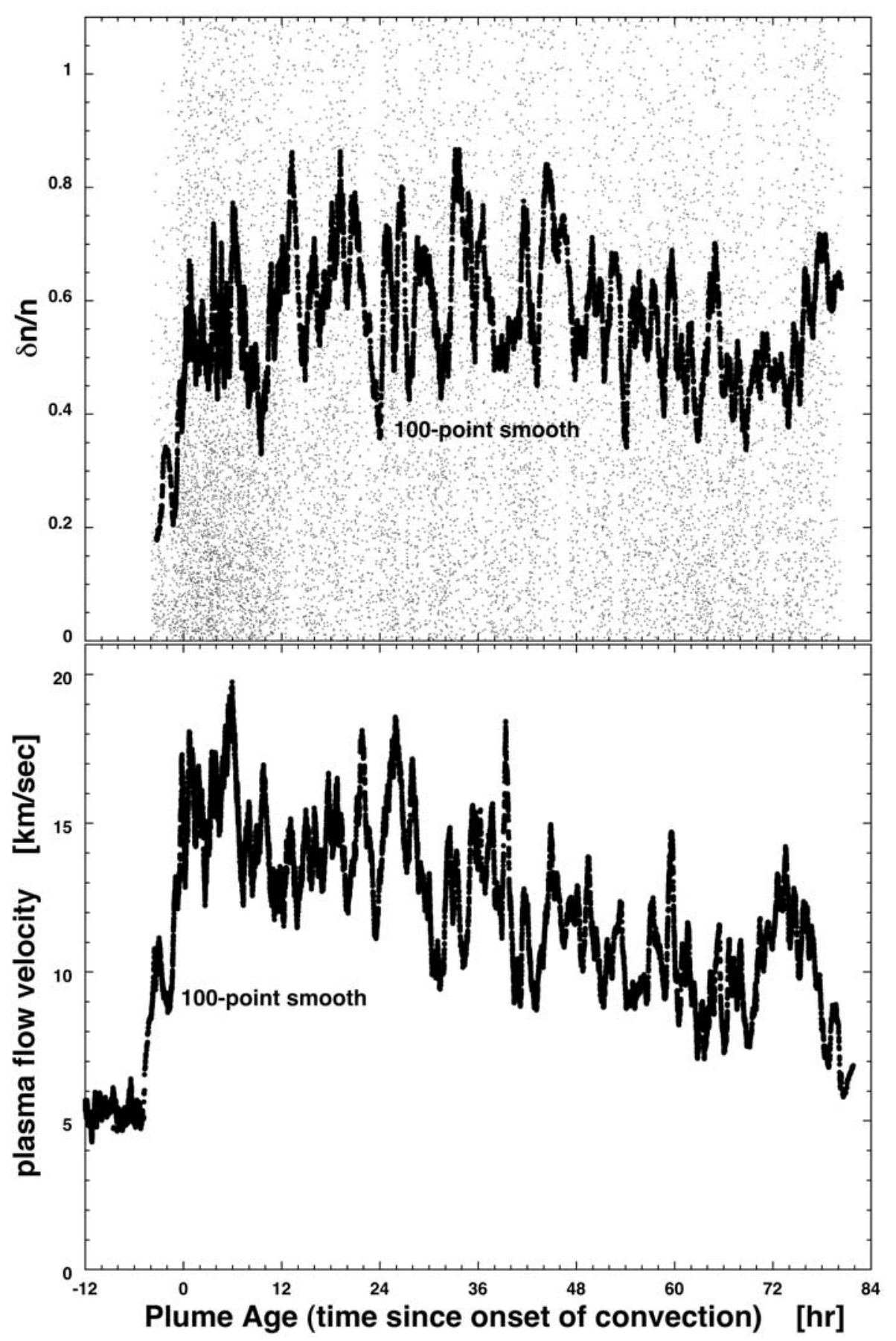

Figure 17. In the top, the fractional change in the measured cold-plasma number density in plumes is plotted as a function of the plume age (gray points), and a 100-point running average is plotted (black points). In the bottom, the plasma flow speed is plotted (not shown), and a 100-point running average is plotted (black points).

(solid curve). The mean of the $\delta n / n$ values is 0.57 . For comparison the fractional variance of sequential random numbers evenly distributed between 0 and 1 is binned (dashed curve); the mean value of the resulting fractional variances is 0.77 . As can be seen by comparing the two distributions in Figure 16, the variance of the plasma density is large, but not as large as random numbers.

[42] In the top of Figure 17 the individual $\delta n / n$ values for plume plasma are plotted (gray points) as a function of the age of the plume (the time since convection onset of the storms). A 100-point running average is plotted as the black points in the top panel. As can be seen by examining the running average, the mean value of $\delta n / n$ increases dramatically as magnetospheric convection onsets at the beginning of the storm, and then is fairly constant with plume age. The increase in lumpiness of the cold plasma with the onset of convection is seen further by comparing the top and bottom of Figure 17. In the bottom panel the measured flow speed 

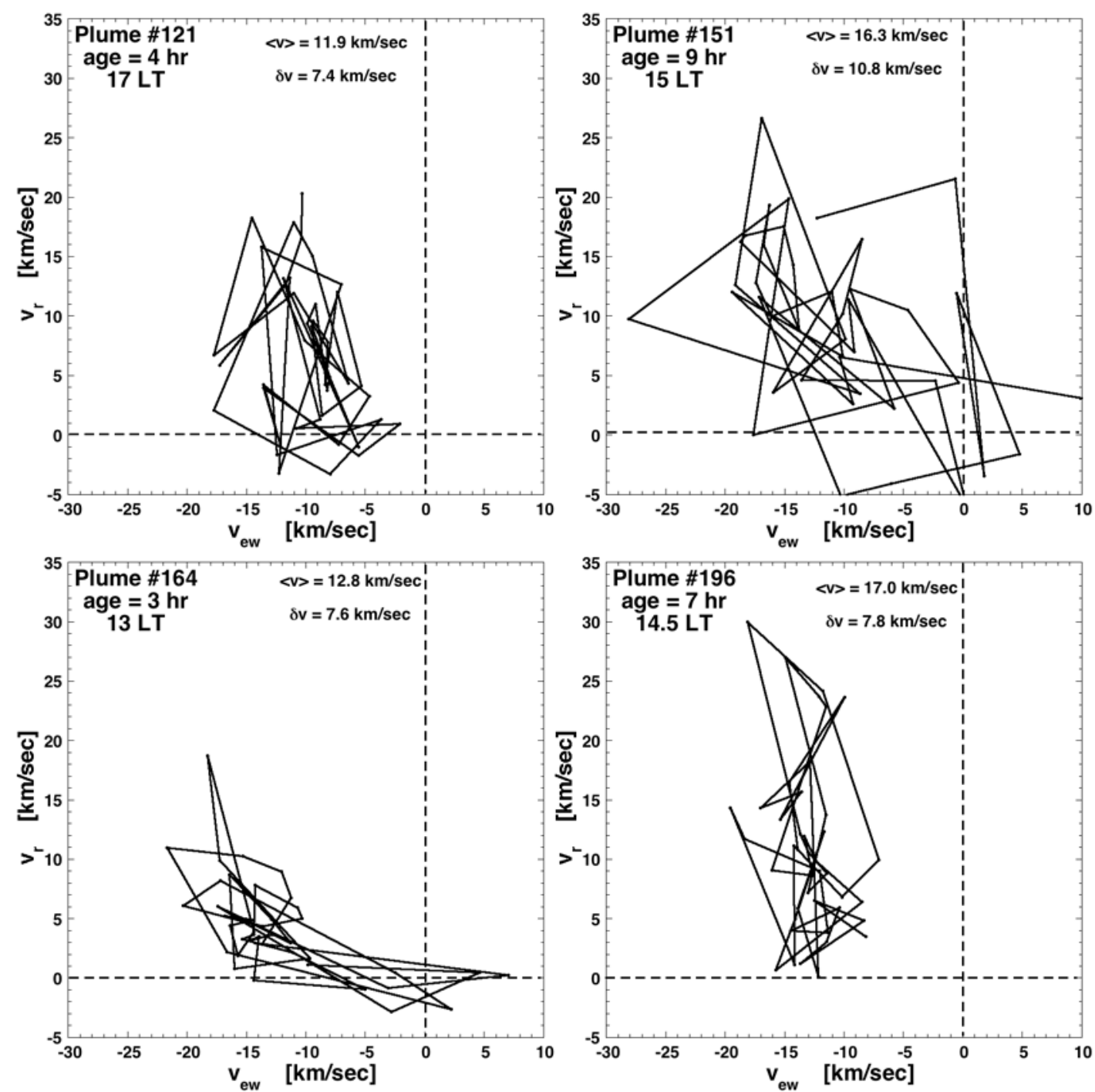

Figure 18. Four hodograms are constructed each from 1 hour of 86-second MPA measurements of the cold-plasma flow velocity. Each 1 hour of data is chosen from a high-density portion of a young drainage plume.

$\left(v_{\mathrm{r}}^{2}+\mathrm{v}_{\mathrm{ew}}^{2}\right)^{1 / 2}$ of the cold plasma (in the spacecraft frame) is plotted as a function of the time since onset of convection: only a 100-point running average is plotted and the data used in this panel includes the outer plasmasphere prior to the storm onset. The dramatic increase in the cold-plasma flow speed at the onset of the storms is clearly seen. When the plasmaspheric plasma begins to flow it becomes lumpy.

\section{Discussion}

[43] In this section three items are discussed: the possibility that the flows in the drainage plumes are turbulent, some possibilities as to why the plumes are lumpy, and future research that is called for.

\subsection{Is the Drainage-Plume Flow Turbulent?}

[44] As will be seen, the measured flow velocities of the drainage-plume plasma show large fluctuations. The question arises: Where do these fluctuations come from? Two possible answers are turbulence in a high-Reynolds-number flow or magnetospheric oscillations. The fact that the drainage plumes are very lumpy (cf. sections 3.8 and 3.2) would support the former, with the plumes being broken up by the flow turbulence.

[45] The fluctuating plasma flows can be examined via the four velocity hodograms in Figure 18. Each hodogram is constructed from 1 hour of MPA cold-plasma flow measurements from high-density portions of four young drainage plumes. Each hodogram is made from a 1-hour sequence of 10 -second snapshots of the flow velocity separated by 86 seconds. Each of the four plots has the same horizontal and vertical scales and $v_{\mathrm{r}}=0$ and $v_{\mathrm{ew}}=0$ are shown as the dashed lines. As the four panels show, the flow fluctuations are substantial. As noted in each panel, the standard deviation of the flow velocity is about half of the mean flow velocity. It is clear in the hodograms of Figure 18 that the 86-sec sampling of the MPA instrument under-resolves the flow velocity. Via Figure 19 these drainage-plume hodograms can be compared with hodograms of two other 

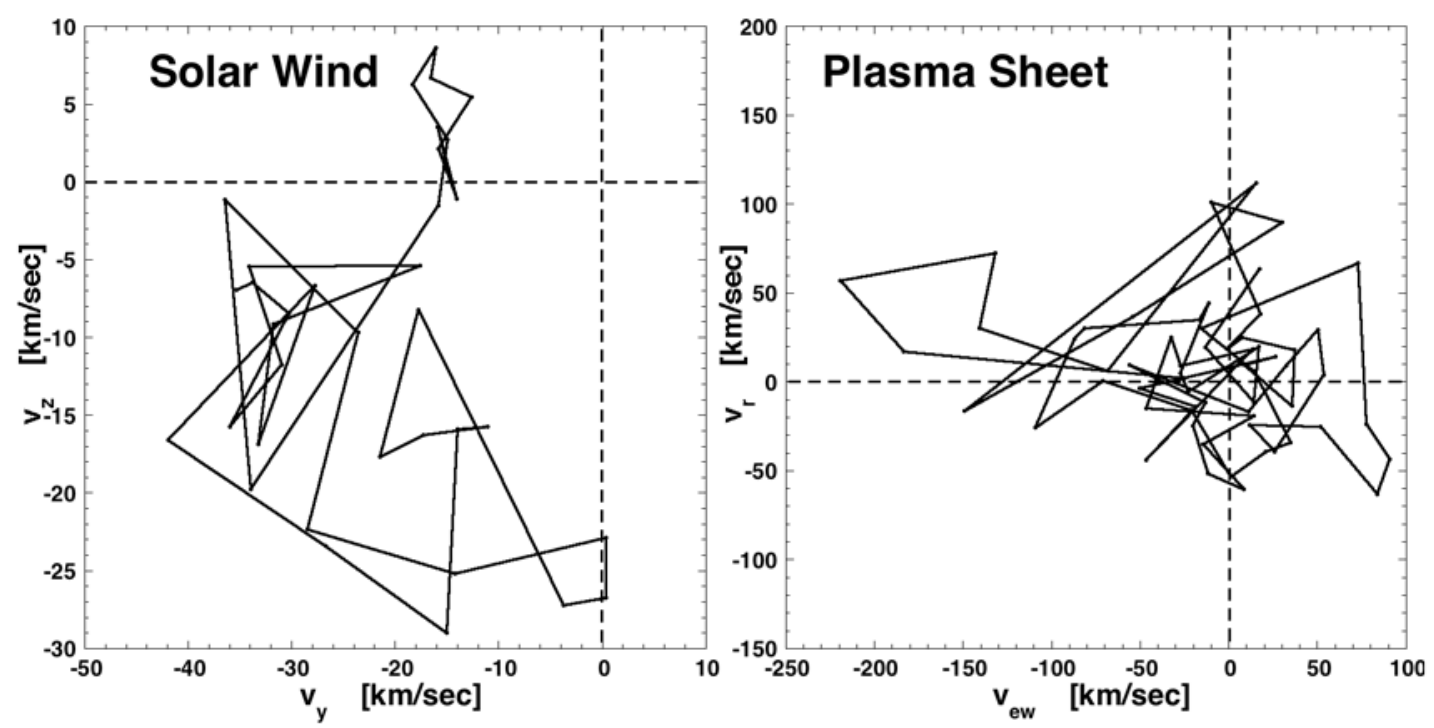

Figure 19. A 1-hour-long velocity hodogram of the (left) solar-wind flow and of the (right) plasmasheet flow are shown. In the left, ISEE-1 SWE measurements from 2100 to 2200 UT on 8 August 1978 in the solar wind were used, and in the right, ISEE-2 FPE measurements from 1245 to 1345 UT on 7 March 1979 near the center of the plasma sheet at $X=-22 R_{\mathrm{E}}$ and $Y=11 R_{\mathrm{E}}$ were used.

plasmas well known to be turbulent: the solar wind [ $\mathrm{Tu}$ and Marsch, 1995; Goldstein et al., 1995] and the Earth's plasma sheet [Borovsky and Funsten, 2003; Weygand et al., 2005]. The hodograms of Figure 19 are also each made using 1 hour of measurement with similar time resolution to the hodograms of Figure 18; the solar-wind hodogram uses 96-second resolution and the plasma-sheet hodogram uses 90-second resolution. The scales of the plots in Figure 19 are not the same as those of Figure 18. As can be seen by comparing the hodograms of these two figures, at a similar time resolution the nature of the flow-velocity fluctuations of the drainage plumes look similar to the nature of the flow-velocity fluctuations of turbulent plasmas.

[46] In Figure 20, the measured amplitude of the velocity fluctuations in plume plasma is plotted as a function of plume age. The magnitude of the change in the vector velocity over 86 seconds $\delta \mathrm{v}$ is taken to be $\delta \mathrm{v}=\left(\left(\mathrm{v}_{\mathrm{r} 1}-\mathrm{v}_{\mathrm{r} 2}\right)^{2}+\right.$ $\left.\left(\mathrm{v}_{\mathrm{ew} 2}-\mathrm{v}_{\mathrm{ew} 1}\right)^{2}\right)^{1 / 2}$, where the 1 and 2 subscripts represent velocities measured at time 1 and time 2 separated by 86 seconds. The $\delta \mathrm{v}$ values for all of the plumes are then

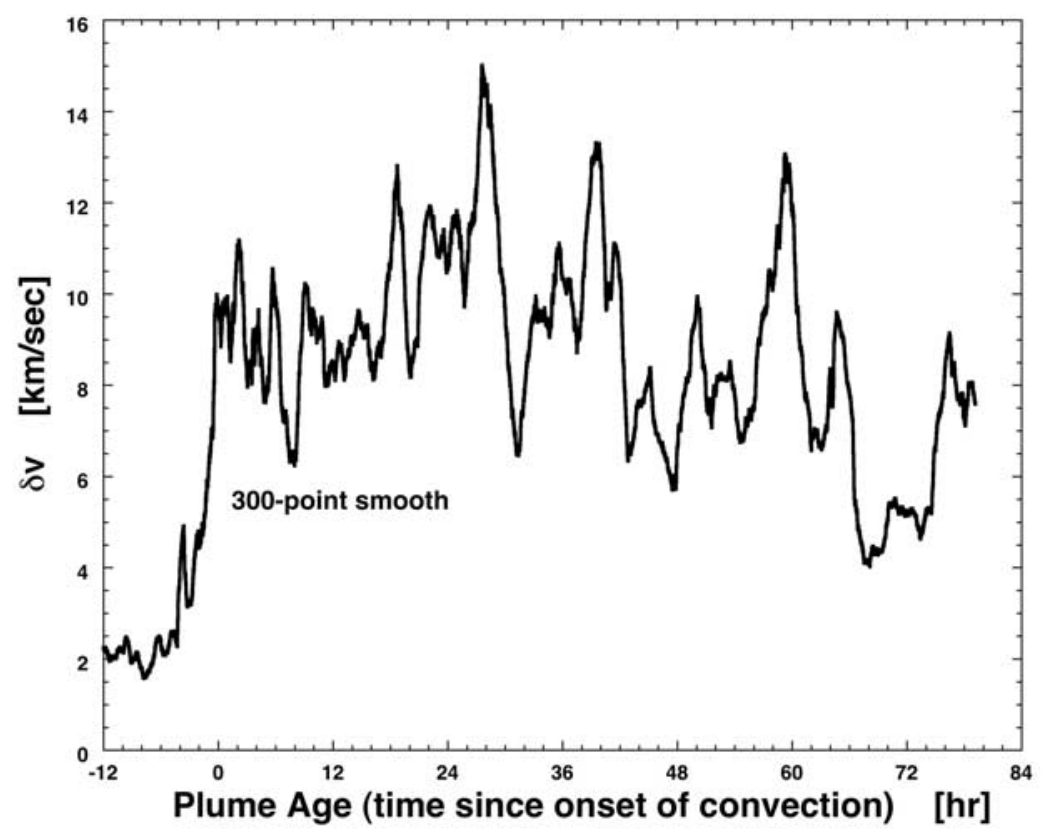

Figure 20. The amplitude of the fluctuations of the cold-plasma flow velocity in plumes is sorted as a function of the age of the plumes, and a 300-point running average is plotted as a function of the age of the plume. The flow fluctuation amplitude is calculated using 86-second measurements. 
Table 2. Timescales for Drainage-Plume Flow and for Plume-Ionosphere Coupling, Along With Characteristic Spatial Scales Assuming a $15 \mathrm{~km} / \mathrm{sec}$ Plasma Flow Velocity

\begin{tabular}{|c|c|c|c|}
\hline & Estimate $(\mathrm{sec})$ & Significance & Characteristic Scale $(\mathrm{km})$ \\
\hline$\tau_{\text {conv }}$ & 2700 & plume width divided by flow speed & $4 \times 10^{4}$ \\
\hline$\tau_{\text {transit }}$ & 280 & transit time to ionosphere and back & 4200 \\
\hline$\tau_{\text {coupl }}$ & 4200 & timescale for full coupling to ionosphere & $6 \times 10^{4}$ \\
\hline$\tau_{\text {disch }}$ & 180 & dielectric discharge time of plasmasphere via resistive ionosphere & 2700 \\
\hline
\end{tabular}

ordered according to plume age and a 300-point running average is applied to produce the curve in Figure 20. As can be seen, the large velocity fluctuations $(\sim 8 \mathrm{~km} / \mathrm{sec})$ onset when the convection in the magnetosphere onsets, i.e., when the plasmaspheric plasma moves.

[47] To gain information about whether the plume-flowvelocity fluctuations could be turbulence, an important indicator is checked. In fluid dynamics, all high-Reynoldsnumber flows are turbulent [Schlichtng, 1979; Novopashin and Muriel, 2002; Ben-Dov and Cohen, 2007]. Determining the Reynolds number of a plasma flow in the magnetosphere is complicated owing to electrodynamic coupling of the plasma to the ionosphere, which can act at a distance on magnetospheric flows in addition to internal "fluid" processes [Borovsky and Funsten, 2003; Borovsky, 2004]. Treating the internal fluid processes first, the Reynolds number of the drainage-plume flow is estimated as follows. The Reynolds of a flow is defined as [e.g., Tritton, 1977; Nakayama and Boucher, 1999]

$$
\mathrm{R}=\mathrm{Lv} / \nu_{\text {kin }}
$$

where $\mathrm{L}$ is a length scale in the flow, $\mathrm{v}$ is a characteristic flow velocity for that length scale, and $\nu_{\text {kin }}$ is the kinematic viscosity of the fluid. (Note that expression (11) can be rewritten as $\mathrm{R}=\tau_{\text {dissip }} / \tau_{\text {conv }}$, where the dissipation timescale $\tau_{\text {dissip }}$ is $\tau_{\text {dissip }}=\mathrm{L}^{2} / \nu_{\text {kin }}$ and the convective timescale $\tau_{\text {conv }}$ is $\tau_{\text {conv }}=\mathrm{L} / \mathrm{v}$.) Depending on the choice of $\mathrm{L}$ and $\mathrm{v}$, the meaning of the Reynolds number changes. To estimate whether a flow should be turbulent, the mean flow velocity and the scale size of the flowing fluid should be chosen for $\mathrm{v}$ and L. Here we will choose $\mathrm{v}=15 \mathrm{~km} / \mathrm{sec}$ to be a typical flow velocity for the plasma of the plume (e.g., Figure 17) and $\mathrm{L}=4 \times 10^{8} \mathrm{~km}$ as a width of the plume flow (e.g., section 3.4). The kinematic viscosity of the plume plasma can be calculated using expression (2.33) of Braginskii [1965] [see also Borovsky et al., 1997b]: $\nu_{\text {kin }}=3 \mathrm{k}_{\mathrm{B}} \mathrm{T}_{\mathrm{i}} /$ $10 \omega_{\mathrm{ci}}^{2} \mathrm{~m}_{\mathrm{i}} \tau_{\mathrm{ii}}$, where $\mathrm{T}_{\mathrm{i}}$ is the ion temperature of the plasma, $\omega_{\mathrm{ci}}$ is the ion-cyclotron period, $\mathrm{m}_{\mathrm{i}}$ is the mass of an ion, and $\tau_{\mathrm{ii}}$ is the ion-ion momentum-exchange collision time. The ion-ion momentum-exchange time for proton-proton Coulomb scattering in the plume plasma can be calculated from expressions (6.2.7) and (6.4.7) of Krall and Trivelpiece [1973]: for a plasma density of $50 \mathrm{~cm}^{-3}$ and temperature $T_{i}=$ $2 \mathrm{eV}$ the collision time $\tau_{\mathrm{ii}}=8.3 \times 10^{4} \mathrm{sec}$ is obtained. Using this value, along with $\omega_{\mathrm{ci}}=9.6 \mathrm{sec}^{-1}$, the kinematic viscosity is $\nu_{\mathrm{kin}}=7.6 \times 10^{4} \mathrm{~cm}^{2} \mathrm{sec}^{-1}$. Using this kinematic-viscosity value in expression (11) along with $\mathrm{L}=4 \times 10^{4} \mathrm{~km}$ and $\mathrm{v}=$ $15 \mathrm{~km} / \mathrm{sec}$ yields a flow Reynolds number of the plume of $\mathrm{R}=8 \times 10^{9}$. Such a high Reynolds number makes nonturbulent flow unlikely [e.g., Montgomery, 1987].
[48] Electrodynamic coupling to the ionosphere can also act as a viscosity which dissipates plasma flows in the magnetosphere [cf. Borovsky and Bonnell, 2001]. A significant difference from ordinary viscous effects is owed to the time delay of the coupling. The electrodynamic coupling of the plume to the ionosphere can be viewed as a transmission-line problem [cf. Goertz and Boswell, 1979] with two timescales which must be estimated: (1) the Alfven-speed transit time between the plume and the ionosphere to which it is magnetically connected and (2) the time to reach full coupling between the generator and the load in the transmission line. These two timescales are derived below and collected into Table 2 .

[49] The first timescale is the round-trip Alfven-speed transit time $\tau_{\text {transit }}$ for an electrical signal in the plume to contact the ionosphere and for the resultant perturbation of the signal to reach back to the plume. For a $70 \% \mathrm{H}^{+}, 20 \%$ $\mathrm{He}^{+}$, and $10 \% \mathrm{O}^{+}$plasma with a number density of $100 \mathrm{~cm}^{-3}$ at $\mathrm{L}=6.6$ in a dipole magnetic field, the Alfven-speed travel time from the equator to the ionosphere is $140 \mathrm{sec}$, so the round-trip transmission-line transit time $\tau_{\text {transit }}$ is $280 \mathrm{sec}$. This timescale is noted in Table 2.

[50] The second timescale stems from the fact that there is an impedance mismatch between the magnetosphere and the ionosphere and so electrical signals must make several transits between the drainage plume and the ionosphere [Goertz and Boswell, 1979; Goertz et al., 1993]. The timescale $\tau_{\text {coupl }}$ to reach full electrodynamic coupling between plasmaspheric and ionospheric motions is $\tau_{\text {coupl }}=\mathrm{N} \tau_{\text {transit }}$, where $\mathrm{N}$ is the number of transits required. The number of transits is governed by the reflection coefficient $r$ of the propagating electrical signal off of the resistive ionosphere; the number required is $\mathrm{N}=1 /(1-r)$. This reflection coefficient $\mathrm{r}$ is given by Scholer [1970] or Maltsev et al. [1974] to be $\mathrm{r}=\mid\left(\Sigma_{\mathrm{A}}-\Sigma_{\mathrm{P}}\right) /\left(\Sigma_{\mathrm{A}}+\right.$ $\left.\Sigma_{\mathrm{P}}\right) \mid$, where $\Sigma_{\mathrm{P}}$ is the height integrated Pedersen conductivity of the ionosphere and $\Sigma_{\mathrm{A}}=\mathrm{c}^{2} / 4 \pi \mathrm{v}_{\mathrm{A}}$ is the Alfven wave admittance of the magnetosphere (evaluated locally in the high-altitude ionosphere) [Scholer, 1970; see also Ramo et al., 1984]. To evaluate $\mathrm{r}$ for the drainage plumes, $\Sigma_{\mathrm{P}}=$ 8 mho is taken (from Figure 8 of Rasmussen et al. [1988] with a $60^{\circ}$ solar inclination angle) and the International Reference Ionosphere [Lincoln and Conkright, 1981] is run at SPDF/Modelweb for 14 hours local time and $\mathrm{L}=$ 6.6 to obtain $\mathrm{v}_{\mathrm{A}}=2.8 \times 10^{4} \mathrm{~cm} / \mathrm{sec}$ in the topside ionosphere, which yields $\Sigma_{\mathrm{A}}=2.5 \times 10^{11} \mathrm{~cm} / \mathrm{sec}=$ 0.28 mho. These $\Sigma_{\mathrm{P}}$ and $\Sigma_{\mathrm{A}}$ values yield a reflection coefficient $r=0.932$. The number of bounces required to attain full coupling is then $\mathrm{N}=15$. So, the coupling time $\tau_{\text {coupl }}=\mathrm{N} \tau_{\text {transit }}$ with $\tau_{\text {transit }}=280 \mathrm{sec}$ and $\mathrm{N}=15$ is $\tau_{\text {coupl }}=4200 \mathrm{sec}$. This timescale is noted in Table 2 . 
[51] For this time-delayed coupling between the flow and the ionosphere, there is a time delay between a flow commencing and the dissipation commencing. The relevant fluid parameter to gauge the properties of such a nonNewtonian flow is the Deborah number D [Harris, 1977; Larson, 1992], which is the ratio of the dissipation-delay timescale to the convective timescale. This is defined

$$
\mathrm{D}=\tau_{\text {coupl }} / \tau_{\text {conv }}
$$

Flows with a Deborah number of unity or greater can behave as high-Reynolds-number flows [e.g., Oztekin et al., 1997; Boffetta et al., 2005], i.e., the delayed dissipation does not inhibit turbulence from growing in intensity. Using $\tau_{\text {coupl }}=4200 \mathrm{sec}$ and $\tau_{\text {flow }}=\mathrm{L} / \mathrm{v}=2700 \mathrm{sec}$ (for the plume width $\mathrm{L}=4 \times 10^{4} \mathrm{~km}$ and the flow speed $\left.\mathrm{v}=15 \mathrm{~km} / \mathrm{sec}\right)$ in expression (12) yields $\mathrm{D}=2$ for the drainage-plume flow electrodynamically coupled to the dayside ionosphere. This value of the Deborah number indicates that the time delay of magnetosphere-ionosphere coupling may be sufficiently large to allow turbulent flow in the magnetosphere.

[52] In conclusion, with the observations and knowledge at hand, there is no reason to believe that the drainage plume flows are not turbulent.

\subsection{Why Are the Plasmaspheric Drainage Plumes Clumped?}

[53] The fact that plasmaspheric drainage plumes are lumpy has been noted in the literature [Spasojevic et al., 2003; Moldwin et al., 2004; Goldstein et al., 2004]. The lumpy drainage plumes may provide an optimal site for plasma waves that either grow on or are ducted by density gradients [e.g., Thorne et al., 1979; Kozyra et al., 1994; Streltsov et al., 2006].

[54] The reason why the plumes are lumpy is not known. (Other $\mathbf{E} \times \mathbf{B}$-drifting dense plasmas are also observed to be structured [e.g., Davis, 1979; Simons et al., 1981].) Four suggestions as to the origin of the lumpiness of the drainage-plume plasma are discussed in the following four paragraphs.

[55] E-cross-B-drifting dense plasma clouds can have mass-density gradients that are unstable to perturbations that fragment the cloud into multiple cloudlets. Often cited is the "E-cross-B gradient-drift instability" [Linson and Workman, 1970; Borovsky and Hansen, 1998].

[56] Velocity shear along the side of $\mathbf{E} \times \mathbf{B}$-drifting plasmas can have charge-sheet and current-sheet instabilities that cause the stream edges to roll up and structure [Hallinan and Davis, 1970; Hallinan, 1976, 1981; Partamies et al., 2001].

[57] There are three plasmasphere-ionosphere coupling timescales that can lead to favored spatial scales in a flowing plasma (see Table 2). Two of these timescales were derived in section 4.1 and the third is derived below. The first timescale is the round-trip Alfven-speed transit time $\tau_{\text {transit }}$ for an electrical signal in the drainage plume to contact the ionosphere and for the resultant perturbation of the signal to reach back to the plume. In section 4.1 the value $\tau_{\text {transit }}=280 \mathrm{sec}$ was obtained. With a flow speed of $15 \mathrm{~km} / \mathrm{sec}$, this leads to a transverse scale size of $4200 \mathrm{~km}$ in the plume wherein a load's response can be mismatched back to a generator. The second timescale $\tau_{\text {coupl }}$ is the time required to reach full electrodynamic coupling between drainage-plume and ionospheric motions. In section 4.1 the value $\tau_{\text {coupl }}=4200 \mathrm{sec}$ was obtained. With a flow speed of $15 \mathrm{~km} / \mathrm{sec}$, this leads to a transverse scale size $6.3 \times 10^{4} \mathrm{~km}$ (which is $10 R_{\mathrm{E}}$ ) in the plume wherein a load's response can be mismatched back to a generator. The third plasmasphere-ionosphere timescale is the dielectric-discharge timescale $\tau_{\text {disch }}$ for drainage-plume motions. This is the time required for the resistive ionosphere (with height-integrated Pedersen conductivity $\Sigma_{\mathrm{P}}$ ) to discharge polarization charge layers on moving magnetospheric plasmas. Using equation (A9) of Borovsky and Steinberg [2006] for $n=100 \mathrm{~cm}^{-3}, \mu=3.1$ (for $70 \% \mathrm{H}^{+}, 20 \% \mathrm{He}^{+}$, and $\left.10 \% \mathrm{O}^{+}\right), \Sigma_{\mathrm{P}}=8 \mathrm{mho}$, and $\mathrm{L}=6.6$, the expression for the discharge time $\tau_{\text {disch }}=8.5 \times 10^{-6} \mathrm{sec} \mu \mathrm{nL}^{7} / \Sigma_{\mathrm{P}}$ yields $\tau_{\text {disch }}=$ $180 \mathrm{sec}$. If Alfven transit-time effects were ignored, $\tau_{\text {disch }}$ would be the equilibration time for magnetospheric and ionospheric motions. A flow speed of $15 \mathrm{~km} / \mathrm{sec}$ combined with a 180 -sec characteristic timescale yields a characteristic spatial scale of $2700 \mathrm{~km}$ in the plume.

[58] Finally, if the plasmaspheric drainage plumes are high-Reynolds-number turbulent flows, then large fluctuations in the concentration (plasma density) of the plume will result [cf. Fackrell and Robins, 1982; Dahm and Dimotakis, 1990]. In particular compare Figure 1 of Crooks and Ramsay [1993] or Figure 2 of Yee et al. [1993] with Figure 5.

\subsection{Future Research}

[59] Higher-resolution density measurements of plasmaspheric drainage plumes are needed to resolve the lumpiness of the plumes and to characterize the distribution of structure scale sizes within the plumes. In particular, a characterization of the evolution of the lumpiness at the onset of convection would provide valuable information to determine the cause of the lumpiness.

[60] Higher-resolution velocity measurements are needed to resolve the plasma-flow-velocity fluctuations observed in the drainage plumes. To discern whether the fluctuations are owed to flow turbulence, sufficient time resolution to permit spectral analysis of the velocity time series is needed, and to rule out magnetospheric oscillations as the source of the velocity fluctuations, multisatellite high-resolution velocity measurements are needed. In particular, a characterization of the evolution of the velocity fluctuations at the onset of magnetospheric convection would greatly aid in determining the cause of the fluctuations.

[61] Sorting the collection of drainage plumes into two categories - (1) plumes in storms that had calms before the storms and (2) plumes in storms that did not have calms before the storms - and separately analyzing the two sets of plumes would be useful [cf. Denton and Borovsky, 2008]. Because the plasmasphere is filled to a greater level in storms with calms, the drainage plumes in those storms are more robust, at least in terms of plasma density and total ion flow. To fully quantify drainage plumes, this separated analysis should be done.

[62] An examination of the warmer-ion populations that are geographically adjacent to the plumes in the dayside magnetosphere during storms is warranted. Prior to crossing 
geosynchronous orbit on the dayside, the flux tubes containing these warm ions passed through the dipolar regions of the magnetosphere at radii larger than the plasmapause; this corresponds to auroral latitudes in the ionosphere. These warm-ion populations may be auroral ion outflows during storms that are convected across the dayside magnetosphere on their way to the magnetopause reconnection line. If these populations are oxygen rich then they may provide a large mass density to support plasma waves that could interact with the radiation-belt and ring-current populations. Also, if they are oxygen rich then these populations may provide a substantial mass flux into the dayside neutral line wherein they may reduce the reconnection rate are hence reduce solar wind/magnetosphere coupling.

[63] Finally, a theoretical examination into the dynamics of flowing plume plasma magnetically connected to the resistive ionosphere is needed to discern the stability of plume flow, the nature and cause of the observed velocity fluctuations, and the nature and cause of the plasma clumping.

\section{Summary}

[64] The findings of this report are summarized as follows (see also Table 1).

[65] Drainage plumes are a persistent feature of storms. In the data set used to study drainage plumes, plumes as long as the 4-day data set were readily found. For the first 4 days of high-speed-stream-driven storms, no falloff in the occurrence rate of plumes was found. It may be that plumes last as long a magnetospheric convection is sustained.

[66] Plasma flow velocities in drainage plumes are sunward. Typical flow velocities are $15 \mathrm{~km} / \mathrm{sec}$ early in storms, decreasing slowly with time as the storms progress.

[67] Drainage plumes weaken with age. The plume plasma density, the plume plasma flow velocity, plume width, and plume mass flux all decrease with the age of the plume.

[68] The amount of mass flux makes sense for draining the outer plasmasphere. The integrated mass fluxes seen in drainage plumes are about $2 \times 10^{26}$ ions $/ \mathrm{sec}$ early in storms and decrease as the storms progress. The integrated mass flux asymptotes to about $2 \times 10^{31}$ ions (or 34 tons of protons) after a few days. About 20 hours is required to drain about half of the mass of the outer plasmasphere.

[69] Drainage plumes are lumpy. Very large variations of the plasma density are seen, clearly under-resolved with 86 -second time resolution. The lumpiness onsets with the onset of magnetospheric convection.

[70] Drainage plumes may be turbulent. Plumes exhibit large velocity fluctuations that are under-resolved with 86 -second time resolution. The large fluctuations commence at the onset of magnetospheric convection. An estimate of the Reynolds number of plume plasma flow yields $\mathrm{R}=8 \times 10^{9}$, a Reynolds number at which any flow is expected to be turbulent, and magnetosphere-ionosphere coupling may not be fast enough to suppress turbulence.

[71] Acknowledgments. The authors wish to thank Bob McPherron for providing an updated list of stream interfaces for this study. This research was supported by the LDRD Program at Los Alamos National Laboratory and by the NSF National Space Weather Program.

[72] Amitava Bhattacharjee thanks Mark Adrian and Jerry Goldstein for their assistance in evaluating this paper

\section{References}

Anderson, E. A., and R. E. Spall (2001), Experimental and numerical investigation of two-dimensional parallel jets, J. Fluids Eng., 123, 401.

Bailey, G. J., N. Balan, and Y. Z. Su (1997), The Sheffield University plasmasphere ionosphere model-a review, J. Atmos. Sol.-Terr. Phys., 59,1541

Bame, S. J., D. J. McComas, M. F. Thomsen, B. L. Barraclough, R. C. Elphic, J. P. Glore, J. T. Gosling, J. C. Chavez, E. P. Evans, and F. J. Wymer (1993), Magnetospheric plasma analyzer for spacecraft with constrained resources, Rev. Sci. Instrum., 64, 1026.

Ben-Dov, G., and J. Cohen (2007), Critical Reynolds number for a natural transition to turbulence in pipe flows, Phys. Rev. Lett., 98, 064503.

Boffetta, G., A. Celani, A. Mazzino, A. Puliafito, and M. Vergassola (2005), The viscoelastic Kolmogorov flow: Eddy viscosity and linear stability, J. Fluid Mech., 523, 161

Borovsky, J. E. (2004), A model for the MHD turbulence in the Earth's plasma sheet: Building computer simulations, in Multiscale Processes in the Earth's Magnetosphere: From Interball to Cluster, edited by J.-A. Sauvaud and Z. Nemecek, p. 217, Kluwer, Dordrecht, Netherlands.

Borovsky, J. E. (2008), The rudiments of a theory of solar-wind/magnetosphere coupling derived from first principles, J. Geophys. Res., 113, A08228, doi:10.1029/2007JA012646.

Borovsky, J. E., and J. Bonnell (2001), The dc electrical coupling of flow vortices and flow channels in the magnetosphere to the resistive ionosphere, J. Geophys. Res., 106, 28,967.

Borovsky, J. E., and M. H. Denton (2006a), The differences between CMEdriven storms and CIR-driven storms, J. Geophys. Res., 111, A07S08, doi:10.1029/2005JA011447.

Borovsky, J. E., and M. H. Denton (2006b), The effect of plasmaspheric drainage plumes on solar-wind/magnetosphere coupling, Geophys. Res. Lett., 33, L20101, doi:10.1029/2006GL026519.

Borovsky, J. E., and M. H. Denton (2008), Relativistic electron dropouts and recovery: A superposed-epoch study of the magnetosphere and the solar wind, J. Geophys. Res., doi:10.1029/2008JA013128, in press.

Borovsky, J. E., and H. O. Funsten (2003), The MHD turbulence in the Earth's plasma sheet: Dynamics, dissipation, and driving, J. Geophys. Res., 108(A7), 1284, doi:10.1029/2002JA009625.

Borovsky, J. E., and P. J. Hansen (1998), The morphological evolution and internal convection of $\mathrm{E} \times \mathrm{B}$-drifting plasma clouds: Theory, dielectricin-cell simulations, and N-body dielectric simulations, Phys. Plasmas, 5 , 3195 .

Borovsky, J. E., and J. T. Steinberg (2006), The "calm before the storm" in $\mathrm{CIR} /$ magnetosphere interactions: Occurrence statistics, solar-wind statistics, and magnetospheric preconditioning, J. Geophys. Res., 111, A07S10, doi:10.1029/2005JA011397.

Borovsky, J. E., M. F. Thomsen, and D. J. McComas (1997a), The superdense plasma sheet: Plasmaspheric origin, solar-wind origin, or ionospheric origin?, J. Geophys. Res., 102, 22,089.

Borovsky, J. E., R. C. Elphic, H. O. Funsten, and M. F. Thomsen (1997b), The Earth's plasma sheet as a laboratory for flow turbulence in high-beta MHD, J. Plasma Phys., 57, 1.

Borovsky, J. E., M. F. Thomsen, D. J. McComas, T. E. Cayton, and D. J. Knipp (1998), Magnetospheric dynamics and mass flow during the November 1993 storm, J. Geophys. Res., 103, 26,373.

Borovsky, J. E., M. Hesse, J. Birn, and M. M. Kuznetsova (2008), What determines the reconnection rate at the dayside magnetosphere? J. Geophys. Res., 113, A07210, doi:10.1029/2007JA012645.

Brace, L. H., H. G. Mayr, and B. M. Reddy (1968), The early effects of increasing solar activity upon the temperature and density of the 1000 kilometer ionosphere, J. Geophys. Res., 73, 1607.

Braginskii, S. I. (1965), Transport processes in a plasma, in Reviews of Plasma Physics Volume 1, edited by M. A. Leontovich, p. 205, Consultants Bureau, New York.

Carpenter, L. D., and C. Park (1973), On what ionospheric workers should know about the plasmapause-plasmasphere, Rev. Geophys. Space Phys., 11,133

Carpenter, D. L., B. L. Giles, C. R. Chappell, P. M. E. Decreau, R. R. Anderson, A. M. Persoon, A. J. Smith, Y. Corcuff, and P. Canu (1993), Plasmasphere dynamics in the duskside bulge region: A new look at an old topic, J. Geophys. Res., 98, 19,243.

Chan, K.-W., and R. E. Holzer (1976), ELF hiss associated with plasma density enhancements in the outer magnetosphere, J. Geophys. Res., 81, 2267.

Chappell, C. R., K. K. Harris, and G. W. Sharp (1970), The morphology of the bulge region of the plasmasphere, J. Geophys. Res., 75, 3848. 
Chappell, C. R., K. K. Harris, and G. W. Sharp (1971), The dayside plasmasphere, J. Geophys. Res., 76, 7632.

Corriveau, A. F., and W. D. Baines (1993), Diffusive mixing in turbulent jets as revealed by a $\mathrm{pH}$ indicator, Exper. Fluids, 16, 129.

Craven, P. D., D. L. Gallagher, and R. H. Comfort (1997), Relative concentration of $\mathrm{He}+$ in the inner magnetosphere as observed by the DE 1 retarding ion mass spectrometer, J. Geophys. Res., 102, 2279.

Crooks, G., and S. Ramsay (1993), A wind tunnel study of mean and fluctuating concentrations in a plume dispersing of a two-dimensional hill, Boundary Layer Meteor, 66, 155.

Dahm, W. J. A., and P. E. Dimotakis (1990), Mixing at large Schmidt number in the self-similar far field of turbulent jets, J. Fluid Mech., 217, 299.

Davis, T. N. (1979), Chemical releases in the ionosphere, Rep. Prog. Phys., 42,1565 .

Dent, Z. C., I. R. Mann, F. W. Menk, J. Goldstein, C. R. Wilford, M. A Cliverd, and L. G. Ozeke (2003), A coordinated ground-based and IMAGE satellite study of quiet-time plasmaspheric density profiles, Geophys. Res. Lett., 30(12), 1600, doi:10.1029/2003GL016946.

Denton, M. H., and J. E. Borovsky (2008), Superposed epoch analysis of high-speed-stream effects at geosynchronous orbit: Hot plasma, cold plasma, and the solar wind, J. Geophys. Res., 113, A07216, doi:10.1029/2007JA012998.

Denton, M. H., M. F. Thomsen, H. Korth, S. Lynch, J. C. Zhang, and M. W. Liemohn (2005), Bulk plasma properties at geosynchronous orbit, J. Geophys. Res., 110, A07223, doi:10.1029/2004JA010861.

Ejiri, M. (1978), Trajectory traces of charged particles in the magnetosphere, J. Geophys. Res., 83, 4798.

Elphic, R. C., L. A. Weiss, M. F. Thomsen, D. J. McComas, and M. B. Moldwin (1996), Evolution of plasmaspheric ions at geosynchronous orbit during times of high geomagnetic activity, Geophys. Res. Lett., 23, 2189.

Elphic, R. C., M. F. Thomsen, and J. E. Borovsky (1997), The fate of the outer plasmasphere, Geophys. Res. Lett., 24, 365.

Fackrell, J. E., and A. G. Robins (1982), Concentration fluctuations and fluxes in plumes from point sources in a turbulent boundary layer, J. Fluid Mech., 117, 1

Foster, J. C., P. J. Erickson, A. J. Coster, J. Goldstein, and F. J. Rich (2002), Ionospheric signatures of plasmaspheric tails, Geophys. Res. Lett. 29(13), 1623, doi:10.1029/2002GL015067.

Foster, J. C., A. J. Coster, P. J. Erickson, F. J. Rich, and B. R. Sande (2004), Stormtime observations of the flux of plasmaspheric ions to the dayside cusp/magnetopause, Geophys. Res. Lett., 31, L08809, doi:10.1029/2004GL020082.

Foster, J. C., W. Rideout, B. Sandel, W. T. Forrester, and F. J. Rich (2007), On the relationship of SAPS to storm-enhanced density, J. Atmos. Sol.-Terr. Phys., 69, 303

Freeman, J. W., H. K. Hills, T. W. Hill, P. H. Reiff, and D. A. Hardy (1977), Heavy ion circulation in the earth's magnetosphere, Geophys. Res. Lett. 4,195

Gallagher, D. L., P. D. Craven, R. H. Comfort, and T. E. Moore (1995), On the azimuthal variation of core plasma in the equatorial magnetosphere, J. Geophys. Res., 100, 23,597.

Garcia, L. N., S. F. Fung, J. L. Green, S. A. Boardsen, B. R. Sande, and B. W. Reinisch (2003), Observations of the latitudinal structure of plasmaspheric convection plumes by IMAGE-RPI and EUV, J. Geophys. Res., 108(A8), 1321, doi:10.1029/2002JA009496.

Goertz, C. K., and R. W. Boswell (1979), Magnetosphere-Ionosphere coupling, J. Geophys. Res., 84, 7239.

Goertz, C. K., L.-H. Shan, and R. A. Smith (1993), Prediction of geomagnetic activity, J. Geophys. Res., 98, 7673

Goldstein, M. L., D. A. Roberts, and W. H. Matthaeus (1995), Magnetohydrodynamic turbulence in the solar wind, Ann. Rev. Astron. Astrophys., $33,283$.

Goldstein, J., B. R. Sandel, W. Forrester, and P. H. Reiff (2003), IMF-driven plasmasphere erosion of 10 July 2000, Geophys. Res. Lett., 30(3), 1146 , doi:10.1029/2002GL016478.

Goldstein, J., B. R. Sandel, M. F. Thonsen, M. Spasojevic, and P. H. Reiff (2004), Simultaneous remote sensing and in situ observations of plasmaspheric drainage plumes, J. Geophys. Res., 109, A03202, doi:10.1029/ 2003JA010281.

Gussenhoven, M. S., and D. Madden (1990), Monitoring the polar rain over a solar cycle: A polar rain index, J. Geophys. Res., 95, 10,399.

Hald, A. (1952), Statistical Theory With Engineering Applications, Sect. 19.12, John Wiley, New York.

Hallinan, T. J. (1976), Auroral spirals 2. Theory, J. Geophys. Res., 81, 3959.

Hallinan, T. J. (1981), The distribution of vorticity in auroral arcs, in Physics of Auroral Arc Formation, edited by S.-I. Akasofu and J. R. Kan, p. 42, AGU, Washington, D. C.

Hallinan, T. J., and T. N. Davis (1970), Small-scale auroral arc distortions, Planet. Space Sci., 18, 1735.
Harris, J. (1977), Rheology and Non-Newtonian Flow, Longman, London, U.K.

Hayakawa, M., N. Ohmi, M. Parrot, and F. Lefeuvre (1986), Direction finding of ELF hiss emissions in a detached plasma region of the magnetosphere, J. Geophys. Res., 91, 135.

Higel, B., and W. Lei (1984), Electron density and plasmapause characteristics at 6.6 Re: A statistical study of GEOS 2 relaxation sounder data, J. Geophys. Res., 89, 1583.

Hoogeveen, G. W., and A. R. Jacobson (1997), Radio interferometrer measurements of plasmasphere density structures during geomagnetic storms, J. Geophys. Res., 102, 14177.

Horne, R. B., N. P. Meredith, R. M. Thorne, D. Heynderickx, R. H. A. Iles, and R. R. Anderson (2003), Evolution of energetic electron pitch angle distributions during storm time electron acceleration to megaelectronvolt energies, J. Geophys. Res., 108(A1), 1016, doi:10.1029/2001JA009165.

Horwitz, J. L., R. H. Comfort, and C. R. Chappell (1990), A statistical characterization of plasmasphere density structure and boundary locations, J. Geophys. Res., 95, 7937

Jordanova, V. K. (2006), Modeling the behavior of corotating interaction region driven storms in comparison with coronal mass ejection driven storms, in Recurrent Magnetic Storms, edited by B. Tsurutani et al., p. 77, AGU, Washington, D. C.

Jordanova, V. K., M. Spasojevic, and M. F. Thomsen (2007), Modeling the electromagnetic ion cyclotron wave-induced formation of detached subauroral proton arcs, J. Geophys. Res., 112, A08209, doi:10.1029/ 2006JA012215.

Kovalevskiy, I. V. (1980), Ion-cyclotron instability in the frontal boundary layer of the geomagnetosphere produced by detached plasma clouds, Geomag. Aeron., 20,338.

Kovalevskiy, I. V. (1981), Cyclotron instability during interaction of detached plasma regions with the plasma sheet during substorms, Geomag. Aeron., 21, 83

Kozyra, J. U., C. E. Rasmussen, R. H. Miller, and L. R. Lyons (1994), Interaction of ring current and radiation belt protons with ducted plasmaspheric hiss 1. Diffusion coefficients and timescales, J. Geophys. Res., 99, 4069

Krall, N. A., and A. W. Trivelpiece (1973), Introduction to Plasma Physics, McGraw-Hill, New York.

Lambour, R. L., L. A. Weiss, R. C. Elphic, and M. F. Thomsen (1997), Global modeling of the plasmasphere following storm sudden commencements, J. Geophys. Res., 102, 24,351.

Larson, R. G. (1992), Instabilities in viscoelastic flows, Rheol. Acta, 31, 213

Lawrence, D. J., M. F. Thomsen, J. E. Borovsky, and D. J. McComas (1998), Measurements of early and late-time plasmasphere refilling as observed from geosynchronous orbit, J. Geophys. Res., 104, 14,691.

Lemaire, J. F., and K. I. Gringauz (1998), The Earth's Plasmasphere, Cambridge Univ. Press, New York.

Liemohn, M. W., A. J. Ridley, J. U. Kozyra, D. L. Gallagher, M. F. Thomsen, M. G. Henderson, M. H. Denton, P. C. Brandt, and J. Goldstein (2006), Analyzing electric field morphology through data-model comparisons of the Geospace Environment Modeling Inner Magnetosphere/Storm Assessment Challenge events, J. Geophys. Res., 111, A11S11, doi:10.1029/ 2006JA011700.

Lincoln, J. V., and R. O. Conkright (1981), International Reference Ionosphere-IRI 79, World Data Center A, Boulder, Colo.

Linson, L. M., and J. B. Workman (1970), Formation of striations in ionospheric plasma clouds, J. Geophys. Res., 75, 3211

Maltsev, Y. P., S. V. Leontyev, and W. B. Lyatsky (1974), Pi-2 pulsations as a result of evolution of an Alfven impulse originating in the ionosphere during a brightening of aurora, Planet. Space Sci., 22, 1519.

Matsui, H., T. Mukai, S. Ohtani, K. Hayashi, R. C. Elphic, M. F. Thomsen, and H. Matsumoto (1999), Cold dense plasma in the outer magnetosphere, J. Geophys. Res., 104, 25,077.

McPherron, R. L., and J. Weygand (2006), The solar wind and geomagnetic activity as a function of time relative to corotating interaction regions, in Recurrent Magnetic Storms, edited by B. Tsurutani et al., p. 125, AGU, Washington, D. C.

Meredith, N. P., R. M. Thorne, R. B. Horne, D. Summers, B. J. Fraser, and R. R. Anderson (2003), Statistical analysis of relativistic electron energies for cyclotron resonance with EMIC waves observed on CRRES, J. Geophys. Res., 108(A6), 1250, doi:10.1029/2002JA009700.

Meredith, N. P., R. B. Horne, R. M. Thorne, D. Summers, and R. R. Anderson (2004), Substorm dependence of plasmaspheric hiss, J. Geophys. Res., 109, A06209, doi:10.1029/2004JA010387.

Moldwin, M. B., M. F. Thomsen, S. J. Bame, D. J. McComas, and K. R. Moore (1994), An examination of the structure and dynamics of the outer plasmasphere using multiple geosynchronous satellites, J. Geophys. Res., 99, 11,475.

Moldwin, M. B., J. Howard, J. Sanny, J. D. Bocchicchio, H. K. Rassoul, and R. R. Anderson (2004), Plasmaspheric plumes: CRRES observations 
of enhanced density beyond the plasmapause, J. Geophys. Res., 109 A05202, doi:10.1029/2003JA010320.

Montgomery, D. (1987), Remarks on the MHD problem of generic magnetospheres and magnetotails, in Magnetotail Physics, edited by A. T. Y. Lui, p. 203, Johns Hopkins Univ. Press, Baltimore, Md.

Nakayama, Y., and R. F. Boucher (1999), Introduction to Fluid Mechanics, Sect. 4.5, Arnold, London, U.K.

Newberry, I. T., R. H. Comfort, P. G. Richards, and C. R. Chappell (1989), Thermal $\mathrm{He}+$ in the plasmasphere: Comparison of observation with numerical calculations, J. Geophys. Res., 94, 15,265.

Novopashin, S., and A. Muriel (2002), Is the critical Reynolds number universal?, J. Exp. Theor. Phys., 95, 262.

Oztekin, A., B. Alakus, and G. H. McKinley (1997), Stability of planar stagnation flow of a highly viscoelastic fluid, J. Non-Newtonian Fluid Mech., 72, 1.

Partamies, N., M. P. Freeman, and K. Kauristie (2001), On the winding of auroral spirals: Interhemispheric observations and Hallinan's theory revisited, J. Geophys. Res., 106, 28,913.

Pasmanik, D. L., V. Y. Trakhtengerts, A. G. Demekhov, A. A. Lyubchich, E. E. Titova, T. Yahnina, M. J. Rycroft, J. Manninen, and T. Turuned (1998), A quantitative model for cyclotron wave-particle interactions at the plasmapause, Ann. Geophys., 16, 332.

Ramo, S., J. R. Whinnery, and T. van Duzer (1984), Fields and Waves in Communication Electronics, Sect.6.6, Wiley, New York.

Rasmussen, C. E., R. W. Schunk, and V. B. Wickwar (1988), A photochemical equilibrium model for ionospheric conductivity, J. Geophys. Res. 93, 9831.

Sandel, B. R., and M. H. Denton (2007), Global view of refilling of the plasmasphere, Geophys. Res. Lett., 34, L17102, doi:10.1029/ 2007GL030669.

Schlichtng, H. (1979), Boundary-Layer Theory, Sect. XVI.a, McGraw-Hill, New York.

Scholer, M. (1970), On the motion of artificial ion clouds in the magnetosphere, Planet. Space Sci., 18, 977.

Simons, D. J., M. B. Pongratz, G. M. Smith, and G. E. Barasch (1981) Prompt striations observed in a barium thermite release at $335-\mathrm{km}$, J. Geophys. Res., 86, 1576.

Smith, A. J., R. B. Horne, and N. P. Meredith (2004), Ground observations of chorus following geomagnetic storms, J. Geophys. Res., 109, A02205, doi:10.1029/2003JA010204.

Sojka, J. J., and G. L. Wrenn (1985), Refilling of geosynchronous flux tubes as observed at the equator by GEOS 2, J. Geophys. Res., 90, 6379.

Spasojevic, M., J. Goldstein, D. L. Carpenter, U. S. Inan, B. R. Sandel, M. B. Moldwin, and B. W. Reinisch (2003), Global response of the plasmasphere to a geomagnetic disturbance, J. Geophys. Res., 108(A9), 1340 doi:10.1029/2003JA009987.

Spasojevic, M., H. U. Frey, M. F. Thomsen, S. A. Fusilier, S. P. Gary, B. R Sandel, and U. S. Inan (2004), The link between a detached subauroral proton arc and a plasmaspheric plume, Geophys. Res. Lett., 31, L04803, doi:10.1029/2003GL018389.

Spiro, R. W., M. Harel, R. A. Wolf, and P. H. Reiff (1981), Quantitative simulation of a magnetospheric substorm 3. Plasmaspheric electric fields and evolution of the plasmapause, J. Geophys. Res., 86, 2261.

Streltsov, A. V., M. Lampe, W. Manheimer, G. Ganguli, and G. Joyce (2006), Whistler propagation in inhomogeneous plasma, J. Geophys. Res., 111, A03216, doi:10.1029/2005JA011357.

Su, Y.-J., J. E. Borovsky, M. F. Thomsen, R. C. Elphic, and D. J. McComas (2000), Plasmaspheric material at the reconnecting magnetopause, J. Geophys. Res., 105, 7591.
Su, Y.-J., M. F. Thomsen, J. E. Borovsky, and D. J. Lawrence (2001a), A comprehensive survey of plasmasphere refilling at geosynchronous orbit, J. Geophys. Res., 106, 25,615.

Su, Y.-J., J. E. Borovsky, M. F. Thomsen, N. Dubouoz, M. O. Chandler, T. E. Moore, and M. Bouhram (2001b), Plasmaspheric material on high-latitude open field lines, J. Geophys. Res., 106, 6085.

Su, Y.-J., M. F. Thomsen, J. E. Borovsky, and J. C. Foster (2001c), A linkage between polar patches and plasmaspheric drainage plumes, Geophys. Res. Lett., 28, 111.

Summers, D., and R. M. Thorne (2003), Relativistic electron pitch-angle scattering by electromagnetic ion cyclotron waves during geomagnetic storms, J. Geophys. Res., 108(A4), 1143, doi:10.1029/2002JA009489.

Summers, D., C. Ma, N. P. Meredith, R. B. Horne, R. M. Thorne, and R. R. Anderson (2004), Modeling outer-zone relativistic electron response to whistler-mode chorus activity during substorms, J. Atmos. Sol.-Terr Phys., 66, 133.

Thomsen, M. F. (2004), Why Kp is such a good measure of magnetospheric convection, Space Weather, 2, S11004, doi:10.1029/2004SW000089.

Thomsen, M. F., J. E. Borovsky, D. J. McComas, R. C. Elphic, and S. Maurice (1998), Magnetospheric response to the CME passage of January 10-11, 1997, as seen at geosynchronous orbit, Geophys. Res. Lett., 25, 2545.

Thomsen, M. F., E. Noveroske, J. E. Borovsky, and D. J. McComas (1999), Calculating the Moments From Measurements by the Los Alamos Magnetospheric Plasma Analyzer, LA-13566-MS, Los Alamos National Laboratory, Los Alamos, New Mexico.

Thorne, R. M., S. R. Church, and D. J. Gorney (1979), On the origin of plasmaspheric hiss: The importance of wave propagation and the plasmapause, J. Geophys. Res., 84, 5241

Thorne, R. M., R. B. Horne, V. K. Jordanova, J. Bortnik, and S. Glauert (2006), Interaction of EMIC waves with thermal plasma and radiation belt particles, in ULF Waves in the Magnetosphere, edited by K. Takahashi et al., p. 213, AGU, Washington, D. C.

Tritton, D. J. (1977), Physical Fluid Dynamics, Sect. 2.4, Reinhold, Berkshire, U.K.

Tsurutani, B. T., and E. J. Smith (1974), Postmidnight chorus: A substorm phenomenon, J. Geophys. Res., 79, 118.

Tsurutani, B. T., and E. J. Smith (1977), Two types of ELF chorus and their substorm dependences, J. Geophys. Res., 82, 5112.

Tu, C.-Y., and E. Marsch (1995), MHD structures, waves and turbulence in the solar wind, Space Sci. Rev., 73, 1.

Webster, D. R., S. Rahman, and L. P. Dasi (2003), Laser-induced fluorescence measurements of a turbulent plume, J. Eng. Mech., 129, 1130.

Weiss, L. A., R. L. Lambour, R. C. Elphic, and M. F. Thomsen (1997) Study of plasmaspheric evolution using geosynchronous observations and global modeling, Geophys. Res. Lett., 24, 599.

Weygand, J. M., et al. (2005), Plasma sheet turbulence observed by Cluster II, J. Geophys. Res., 110, A01205,.doi:10.1029/2004JA010581.

Wilson, G. R., J. L. Horwitz, and J. Lin (1992), A semikinetic model for early stage plasmasphere refilling. 1. Effects of Coulomb collisions, J. Geophys. Res., 97, 1109.

Yee, E., D. J. Wilson, and B. W. Zelt (1993), Probability distributions of concentration fluctuations of a weakly diffusive passive plume in a turbulent boundary layer, Boundary Layer Meteor, 64, 321.

J. E. Borovsky, Los Alamos National Laboratory, Mail Stop D466, Los Alamos, NM 87545, USA. (jborovsky@lanl.gov)

M. H. Denton, Department of Communication Systems, Lancaster University, Lancaster LA1 4WA, UK 